\title{
(1)
}

UNIVERSIDAD PERUANA DE CIENCIAS APLICADAS

ESCUELA DE POSTGRADO

PROGRAMA DE MAESTRÍA EN DIRECCIÓN ESTRATÉGICA DEL FACTOR HUMANO

\section{LA ESTRATEGIA DE COMUNICACIÓN INTERNA Y SU IMPACTO EN LA FINALIZACIÓN DE UNA HUELGA GENERAL INDEFINIDA TRABAJO DE INVESTIGACIÓN}

Para optar el grado académico de Maestro en Dirección Estratégica del Factor Humano

\author{
AUTORES \\ Acevedo Lecca, Ana Melva (0000-0001-6217-7010) \\ Pestana De Marzi, Carina (0000-0002-2341-9547) \\ Rossi Sánchez, Rosa Mercedes (0000-0003-3923-2338) \\ ASESOR \\ Coquelet Castagnino, Giselle (0000-0003-4993-3955)
}

Lima, diciembre de 2018 


\section{RESUMEN}

El líder dentro de una organización es muy importante, y se considera un comunicador muy efectivo. A través de un plan de comunicación interna, con información clara, sencilla y transparente, se logró influenciar en la finalización de una huelga sindical, mejorando el clima laboral.

Se desarrolló previamente a los líderes en habilidades de comunicación y se diseñó el plan de comunicación interna, contando con información actualizada y estructurada en un lenguaje claro y sencillo, de fácil entendimiento de los jefes en su mayoría ingenieros de producción, y a su vez, entendible para sus subordinados, en su mayoría operarios y técnicos. Fue así que durante el proceso de negociación colectiva, fueron los líderes, los protagonistas de la información oficial de la negociación colectiva, posicionándolos como portavoces de la empresa frente a sus operadores, fortaleciendo su liderazgo a través de diálogos abiertos y objetivos, generando influencia fuera de la mesa de negociación.

Palabras clave: Liderazgo, comunicación, negociación, clima laboral 


\begin{abstract}
The leader within an organization is very important, and is considered a very effective communicator. Through an internal communication plan, with clear, simple and transparent information, it was possible to influence the end of a union strike, improving the working environment.
\end{abstract}

The leaders in communication skills were previously developed and the internal communication plan was designed, with up-to-date and structured information in a clear and simple language, easily understood by the chiefs, mostly production engineers, and in turn, understandable for his subordinates, mostly workers and technicians. It was so during the collective bargaining process, were the leaders, the protagonists of the official information of collective bargaining, positioning them as spokespersons of the company in front of its operators, strengthening its leadership through open dialogues and objectives, generating influence outside of the negotiation table.

Keywords: Leadership, communication, negotiation, work environment 


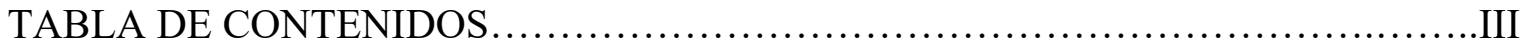

ÍNDICE DE FIGURAS...............................................................

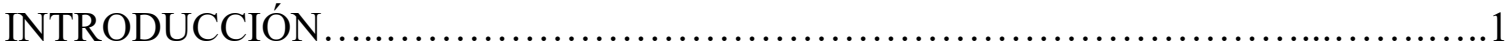

TEMA, PROBLEMA, HIPÓTESIS, OBJETIVO GENERAL $\ldots \ldots \ldots \ldots \ldots \ldots \ldots \ldots \ldots \ldots . . \ldots \ldots$

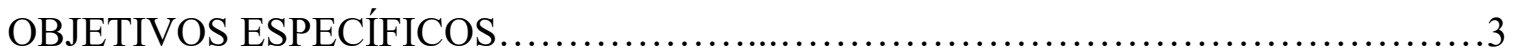

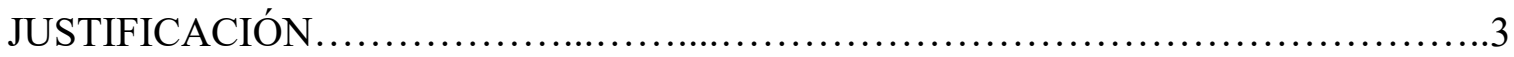

CAPÍTULO I: MARCO TEÓRICO...............................................

1.1 Relaciones Laborales y Sindicales en el Sector Industrial Peruano...................5

1.1.1 Gestión estratégica de las relaciones laborales y Sindicales................5

1.1.2 Particularidades de la Negociación Laboral en el Perú......................7

1.2 Comunicación Interna Organizacional.....................................13

1.2.1 Principales canales de la Comunicación Interna...........................16

1.2.2 Proceso de Comunicación en Cascada.........................................................20

1.2.3 El rol de la alta dirección en la comunicación interna......................22

CAPÍTULO II: LAS RELACIONES SINDICALES EN UNA EMPRESA INDUSTRIAL

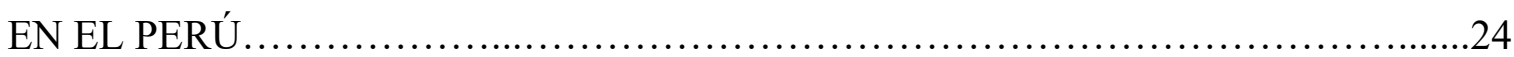

2.1 El sector minero y PBI en el Perú...........................................24

2.2 Marco Legal de pago de utilidades......................................27

2.3 Huelgas como medidas de presión en el Perú.................................28

2.4 Contexto Sindical en una empresa industrial en el Perú.........................29

2.4.1 Estrategia de la negociación sindical en el período 2018..................31

CAPÍTULO III:ESTRATEGIA DE LA COMUNICACIÓN EN CASCADA..............36

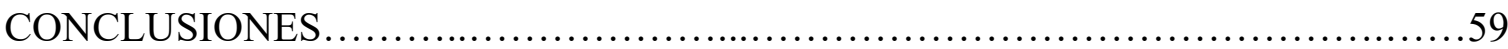

RECOMENDACIONES........................................................62

REFERENCIAS BIBLIOGRÁFICAS............................................64

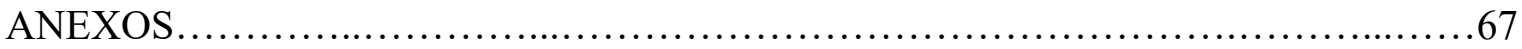




\section{ÍNDICE DE FIGURAS}

Figura 1. La infografía explica las fases de la comunicación en cascada. Adaptado de «Sistema de información en cascada», por Harvard Deusto Business Review, 1996

Figura 2. Flujo muestra la comunicación de los líderes. Adaptado de «Flujo de comunicación en cascada» por elaboración propia, 2018

Figura 3. Formato muestra el protocolo de comunicación. Adaptado de «Formato de comunicación en cascada» por elaboración propia, 2018

Figura 4. Formato muestra la medición de la comunicación de los líderes. Adaptado de «Cumplimiento de comunicación en cascada» por elaboración propia, 2018

Figura 5. Formato muestra la efectividad de comunicación. Adaptado de «Formato de efectividad mes de enero 2018» por elaboración propia, 2018 50

Figura 6. Formato muestra la efectividad de comunicación. Adaptado de «Formato de efectividad mes de febrero 2018» por elaboración propia, 2018.

Figura 7. Formato muestra la efectividad de comunicación. Adaptado de «Formato de efectividad mes de marzo 2018» por elaboración propia, 2018 


\section{INTRODUCCIÓN}

El tema de investigación surge a causa de un proceso de negociación sindical en una empresa de industrial ubicada en Perú, ocurrido dentro del primer trimestre del año 2018.

En dicha empresa, hacía más de 05 años que no se generaba repartición de utilidades, ésta otorgaba por convenio colectivo a sus operadores, un bono que compensara el no pago de utilidades. Tanto la empresa como el sindicato habían acordado que desde que se reestablezca la repartición de utilidades cesaba el otorgamiento de esta bonificación extraordinaria.

La materia del conflicto se originó dentro del período que comprendía el pago de utilidades por el año 2017, y pese a lo acordado con el sindicato, éste venía requiriendo a la empresa que se mantenga el pago de la bonificación extraordinaria. Sin embargo, la Empresa había comunicado a todos sus trabajadores que no procedería con el otorgamiento del bono para el año 2017 y que solo tenía la obligación de pagar las utilidades de acuerdo a ley. Esta bonificación extraordinaria representaba para la empresa el desembolso más de diez millones de soles.

Dado que la empresa avizoraba este escenario con su sindicato, para el primer trimestre del año 2018, desarrolló una estrategia de negociación y comunicación interna con el fin de abordar el conflicto sindical a través de sus líderes quienes serían los portavoces de los mensajes de la empresa hacia sus trabajadores, y de esa manera reducir las consecuencias de una huelga. 
TEMA, PROBLEMA, HIPÓTESIS, OBJETIVO GENERAL

\section{Tema:}

Analizar la estrategia de la comunicación interna dentro de una empresa de industrial para reconocer el impacto que generó en el proceso de finalización de una huelga sindical.

\section{Problema:}

Dentro de un proceso de negociación colectiva, la comunicación no forma parte de una estrategia, lo cual puede generar un impacto desfavorable en el momento de crisis de una negociación, como lo es una huelga.

\section{Hipótesis}

Diseñar una estrategia de comunicación interna que contribuya a la finalización de una huelga indefinida.

\section{Objetivo General:}

Determinar de qué manera una estrategia de comunicación impacta en el desarrollo y finalización de una huelga general indefinida 


\section{OBJETIVOS ESPECÍFICOS}

- Determinar cómo el liderazgo de la empresa implementó la estrategia de comunicación hacia sus equipos de operadores dentro del proceso de negociación y huelga indefinida.

- Analizar la reacción de los trabajadores sindicalizados frente a la estrategia de comunicación interna de la empresa.

- Identificar el valor agregado de la comunicación en cascada dentro de la empresa durante los días de huelga, considerando las pérdidas económicas por la pérdida de producción.

\section{JUSTIFICACIÓN}

La comunicación en una empresa donde una parte importante de colaboradores son operarios y sindicalizados. La forma cómo los mensajes son llevados y manejados en una situación de huelga puede afectar la negociación y estado actual de la empresa. Asimismo, es importante definir qué tipo de comunicación se brindará, a través de qué canales, quienes son aquellos que brindarán la comunicación, de qué tipo, entre otros. Es de gran interés de la empresa, que la comunicación sea clara y efectiva, de esta manera se logre un buen resultado con el sindicato, ya que si este no está contento se paraliza la producción y la empresa pierde una suma importante de dinero cada día.

La presente tesis analizará de qué manera el proceso de comunicación contribuyó en la finalización de una huelga general indefinida.

Lo que se propone en el presente trabajo, es analizar la estrategia de comunicación y como ésta contribuyó a la conclusión de una huelga indefinida en una empresa de industrial en el Perú, ya que cada día de paralización de labores constituye pérdidas irreparables en la producción de la 
empresa, así como riesgos en seguridad y posibles accidentes de trabajo, toda vez que el clima se torna tenso e incierto.

Lo que buscamos en la presente tesis es mostrar como la estrategia de comunicación en cascada generó un impacto positivo en el proceso de negociación sindical, lo que a su vez repercutió en clima laboral, relaciones interpersonales y costos para la empresa. 


\section{CAPÍTULO I: MARCO TEÓRICO}

En el presente capítulo se desarrollan algunos conceptos que apoyan el presente tema de investigación, a través de los aportes de diversas fuentes y autores:

\subsection{Relaciones Laborales y sindicales en el sector industrial peruano}

\subsubsection{Gestión estratégica de las Relaciones Laborales y Sindicales}

Las relaciones laborales se refieren, al estudio de los diferentes aspectos de la regulación del trabajo, en especial a aquellos relativos al establecimiento y aplicación de normas laborales, establecidas por el Ministerio de Trabajo. Atendiendo a sus principales funciones, define las relaciones entre el empresario que aporta el capital y el trabajador que a cambio de un sueldo presta sus servicios (CTAIMA Outsourcing \& Consulting, 2011).

Encierra las relaciones que tiene el trabajador con la empresa, tanto de manera individual como colectiva, con la intervención del Estado que desempeña el rol de regulador y legitimador del orden social, integrador de las partes en conflicto y coordinador de la negociación laboral.

Es importante tener en cuenta que las relaciones laborales; individuales son las que un trabajador en forma aislada establece con el empleador y colectivas son las que establece un sindicato en representación de los trabajadores con una empresa (Valencia, 2014).

Para el tema en estudio, es importante indicar que cuando hagamos referencia a relaciones laborales nos estaremos refiriendo a las colectivas de trabajo, es decir la relación que se da entre el sindicato y empresa. 


\section{Sindicato}

Sindicato es una organización que desde un principio busca, mediante el poder colectivo, busca el respeto a los derechos de los trabajadores. La influencia del sindicato no es solo dentro de la empresa, también actúa fuera de ella, es decir, ejerce poder social sobre otras organizaciones e instituciones públicas.

En el Perú, la libertad sindical está prevista dentro de la Constitución peruana, donde se reconoce el derecho de los trabajadores tanto del sector público como privado a la sindicalización y establece la libertad sindical como un indicador del mismo. No se requiere autorización previa para formar sindicato, estos se pueden conformar según ocupación, afiliación patronal o zona geográfica. Las restricciones que existen son: (1) para el caso de trabajadores temporales no pueden afiliarse al mismo sindicato de los trabajadores estables y (2) los trabajadores extranjeros no pueden asumir puestos de liderazgo dentro del sindicato, del mismo modo con los trabajadores migrantes. (Niko R'L, 2014)

Los sindicatos se clasifican en tres tipos:

o Sindicatos de clase; concede mayor importancia a las movilizaciones que a la colección colectiva. Tienden a velar por los intereses generales de los trabajadores

o Sindicatos económicos; focaliza su acción en la empresa, por lo cual, recurre constantemente a la negociación colectiva y busca tener el control en el centro de labores.

o Sindicatos de concertación; percibe objetivos económicos y sociales más amplios, por ello involucra en sus iniciativas al Estado. 
Considerando que el objetivo final de la empresa es ser lo más rentable posible gestionando eficientemente los recursos que cuenta, por ello, la relación entre empresa y trabajadores se encuentra en constante negociación, a fin de satisfacer cada parte sus intereses.

La conflictividad natural de las relaciones laborales puede poner en riesgo, la sostenibilidad del negocio, por ello es importante gestionarla como un elemento clave del éxito empresarial, se debe tener en cuenta que cuando se incorpora un nuevo colaborador a la empresa, (Albalate, 2011) se contrata al conjunto de habilidades, capacidades y potencialidades que son resultados de procesos que no dependen de una simple relación contractual comercial, sino influyen otros factores de la persona como actitudes, principios, valores, expectativas, entre otros. Por ello, el trabajador puede actuar y tomar decisiones fuera del contexto esperado por la empresa y viceversa, en tal sentido, si una de las partes percibe que no está recibiendo lo que merece, que no existe en la relación de reciprocidad, un manejo equilibrado de sus intereses, esta situación generara conflicto de intereses. (Barrera, 2004)

Las relaciones laborales, que no se enfoquen en prevención, manejo y solución de conflictos pueden generar consecuencias negativas que ya que el conflicto laboral trae consigo una reducción en la productividad y utilidades, reduce la posibilidad de nuevos proyectos, generar ahorros y cualquier otra acción que contribuya a cambios positivos para la buena marcha de la empresa.

\subsubsection{Particularidades de la Negociación Laboral en el Perú}

En un proceso de negociación es importante conocer a detalle al oponente, sus fortalezas y debilidades, obtener la mayor cantidad de información que ayudará a cada una de las partes a tener 
mejores argumentos. Asimismo, deben estar como puntos importantes, los objetivos que se proponen para conseguir la negociación de acuerdo a las necesidades de cada parte, los cuales deben ser realistas, claros, concretos y bien definidos.

Para obtener una negociación exitosa, es importante que cada una de las partes tenga un orden de las ideas que transmite, y la habilidad para negociar, entender y precisar. Asimismo, desarrollar con cierta habilidad los argumentos y conseguir el trato.

Finalmente, al tener una preparación con tiempo, dará al negociador un nivel mayor de confianza, ya que tendrá los objetivos claros y podrá escuchar activamente a su oponente. Asimismo, podrá expresarse de manera positiva intentando comprender los puntos de vista del oponente, y optimizará el tiempo de las entrevistas dirigiéndose directamente al tema sin divagar.

\section{Proceso de la negociación}

En todo proceso de negociación, ambas partes buscan un objetivo común el cual es llegar a satisfacer sus necesidades e intereses, aquello que les impulsó a negociar. Para ello, existen diferentes etapas que se describen a continuación.

o Etapa de la preparación: la cual es considerada la etapa más importante del proceso ya que el negociador debe prestar atención a todos detalles debido a que con la información recopilada de la parte contraria, se pueden preparar muy buenos argumentos. Asimismo, se definen los intereses, se realiza la búsqueda de información y se establecen los objetivos que se desea lograr. En esta etapa se presta atención a todos aquellos aspectos y detalles que pueden influir en cada uno de los objetivos e intereses particulares que se pretenden conseguir con la negociación. 
o Etapa de las estrategias: en la cual se buscan opciones, tácticas y posibles alternativas. Esta etapa será más efectiva al conseguir la mayor información del oponente lo cual permite ajustar mejor las estrategias para la negociación.

o Etapa de desarrollo: en la cual se buscan estilos, alternativas, objeciones y propuestas. En ella, los negociadores ponen en juego sus habilidades personales y profesionales, demuestran la dedicación en tiempo de preparación. La estrategia aplicada por cada uno, determinará la suerte de los objetivos a negociar.

o Etapa de acuerdo y conclusión: en la cual se buscan concesiones, contratos verbal o escrito y una evaluación. Se considera terminada cuando los negociadores se han adaptado, flexibilizado e intercambiado ideas y han logrado llegar a un acuerdo.

\section{Estilos de Negociación}

De acuerdo a las necesidades, cada parte optará por un estilo de negociación donde influyen tres factores importantes. En primer lugar, el carácter temporal de la negociación; por ejemplo, si es una sola negociación, es probable que sea de tipo pragmático ya que sólo se desea conseguir el mayor beneficio y no existirá ningún tipo de relación posterior. En caso de relaciones de largo plazo; por ejemplo, con colaboradores de la misma empresa o proveedores, la tendencia será de tipo humanista, importando los sentimientos de las demás personas involucradas. También, otro factor que influye son las expectativas que tiene cada una de las partes debido a que, si son altas o bajas, habrá mayor tensión o mayor fluidez y cooperación.

Finalmente, el factor del clima de negociación obtenido, el cual estará relacionado a la seguridad de cada una de las partes de acuerdo con la preparación que han tenido. 
Se consideran cinco estilos de negociación:

o Formalista: toma en cuenta procesos ya establecidos, perfeccionista, resiste la presión, posee un alto grado de autocontrol, realista, prefiere argumentos por escritos que verbales.

o Cooperativo: Relación cordial y de confianza, evita la confrontación y se busca una solución para ambos, no suele ocultar información, prefiere la comunicación oral a la escrita, suele escuchar y busca la cooperación.

o Diplomático: Busca el equilibro entre las partes, paciente, analítico, equilibrado, gran capacidad de diálogo, les da importancia a las pruebas demostrativas, es discreto con la información y no se compromete con lo que no se puede cumplir.

o Impositivo: Busca vencer al opositor, firme, duro, analiza cada argumento expuesto, es explícito, directo, preciso, habla más de lo que escucha e intimida con el lenguaje verbal y gestos.

o Dirigente: Busca el ganar-ganar, es objetivo y cordial, tiene capacidad de análisis y síntesis, confía en la otra parte, domina las técnicas de comunicación, es firme y respeta al oponente.

\section{Grupos en la negociación}

En toda negociación, es importante el intercambio de información entre personas, conocer los intereses y motivaciones del oponente. Empezando desde la raíz del problema, de dónde vienen las necesidades y brindarle argumentos específicos para llegar a la solución. 
Las negociaciones dentro de las empresas, no siempre se realizan con una sola persona sino también con grupos o colectivos externos. Por ejemplo, con sindicatos donde la negociación es un medio para la consecución de otros fines.

Los grupos tienen la necesidad de comunicarse, de la calidad de esta comunicación depende la eficacia del grupo y de conseguir un acuerdo. Uno de los sistemas básicos de la comunicación es de forma en estrella, es decir, toda negociación la hacen los integrantes a través de un líder. Este tipo de comunicación es más exacta y se produce con presión.

El negociador con grupos tiene como objetivo, obtener acuerdos que favorezcan a ambas partes. Previo a ello, deberá conocer bien al grupo con el que negociará, identificando los roles positivos los cuales harán que se logre un acuerdo y los negativos que frenan el proceso de negociación. Es importante observar y evaluar los comportamientos, al grupo en sí mismo, las posturas y jerarquías que asumen. Además, la posición ante la cultura y las normas del grupo; si existe un líder quien representa al grupo, con capacidad organizativa o intelectual, y también con autoridad de tomar decisiones.

\section{Negociación Laboral en el Perú}

La negociación colectiva puede ser definida como el conjunto de relaciones y procesos de comunicación y acercamiento por intermedio de los representantes de los trabajadores y de la empresa orientado a lograr acuerdos en materia remunerativa, mejores condiciones de trabajo y productividad que regulen las relaciones laborales entre dichas partes. (Ministerio de Trabajo y Promoción del Empleo) 
En el Perú hay tres niveles de negociación:

o De empresa, cuando se aplica a todos los trabajadores de la empresa o a los de una categoría, sección o establecimiento determinado de aquella. (Ministerio de Trabajo y Promoción del Empleo)

o De rama de actividad; cuando comprende a todos los trabajadores de una misma actividad económica (Ministerio de Trabajo y Promoción del Empleo)

o De gremio; cuando se aplica a todos los trabajadores que desempeñan una misma profesión, oficio o especialidad en diferentes empresas. (Ministerio de Trabajo y Promoción del Empleo)

En la Negociación colectiva, existen tres etapas:

o Negociación directa: es la primera etapa del procedimiento de negociación colectiva, que se inicia dentro de los diez primeros días calendarios de presentación del pliego de reclamos, debiendo este último ser admitido por la Autoridad Administrativa de Trabajo. En esta etapa las partes se reúnen para buscar una solución al pliego de reclamos, suscribiendo acuerdos parciales o el convenio colectivo en caso de llegar a un acuerdo final. (Ministerio de Trabajo y Promoción del Empleo)

o Conciliación: es la etapa del procedimiento de negociación colectiva mediante la cual un conciliador aplicando los principios de flexibilidad y simplicidad debe desempeñar un rol activo en la generación de acuerdo entre las partes con la finalidad que estas lleguen a una solución al pliego de reclamos. (Ministerio de Trabajo y Promoción del Empleo)

o Arbitraje: es una etapa del procedimiento de negociación colectiva, que se desarrolla mediante alternativa de la huelga consistiendo en la decisión de las partes orientada a 
que un árbitro unipersonal o un tribunal arbitral, según sea el caso, lleve el denominado proceso arbitral, a través del cual y habiendo recibido una propuesta final de ambas partes, emita un Laudo Arbitral que recoja en su integridad una de las propuestas antes mencionadas. (Ministerio de Trabajo y Promoción del Empleo)

\subsection{Comunicación interna organizacional}

La relación entre las organizaciones y empleados se fortalece mediante la comunicación interna, que va más allá de la difusión de memorandos, correos electrónicos y publicaciones, nos permite construir una cultura corporativa basada en valores que permitan impulsar el cambio de la organización desde adentro hacia afuera.

El empleado actual es, en sus valores, expectativas y necesidades, una persona diferente de los empleados de décadas pasada. Son personas con una mejor formación, que tienen expectativas más altas que generaciones anteriores respecto a los objetivos de su trayectoria laboral y demuestran mayor interés por conocer y entender la empresa donde trabajan.

Las condiciones de trabajo también han cambiado, las jornadas laborales son más extensas, hay mayor carga de trabajo y mayor foco en resultados. En los últimos años la externalización de puestos de trabajo a países emergentes ha originado incertidumbre, desasosiego y frustración entre los empleados. Todos estos factores hacen que los empleados sean más críticos en la forma y el contenido que les comunica la alta dirección, así como el compromiso en la estrategia global de la empresa.

Actualmente, los empleados exigen una participación activa en la comunicación efectiva que impulsa el cambio organizacional. En este nuevo entorno, la comunicación debe ser un proceso de dos direcciones; el empleado de hoy espera que (1) cuando se les pide su opinión y se toman tiempo 
para responder brindando aportes y (2) la dirección los escuche y tome en cuenta sus aportes. En la mayoría de empresas, la alta dirección toma las decisiones sin tomar en cuenta a los empleados, generando que ellos se sientan ajenos a la empresa y poco valorados, en consecuencia, sean reacios a aceptar la implementación de nuevos cambios en la empresa.

En la medida que la competencia por la contratación de talento se intensifica, es importante disponer de un adecuado y sólido programa de comunicación interna que pase a ser fundamental para captar y retener a talento humano, actores esenciales en la consecución de resultados de la organización.

\section{Organización de la función de comunicación interna}

Para desarrollar un buen programa de comunicación interna es importante; (1) Descubrir cómo se ha respondido a las siguientes preguntas ¿quién comunica?, ¿qué comunica? y ¿cómo comunica? y (2) Conocer la disposición de los empleados hacia la empresa. Saber la opinión de los empleados nos permite identificar qué pilares hay que mover para introducir mejoras en la empresa, así como si está dando respuesta a las expectativas creadas.

Cuando la alta dirección conoce la valoración que hacen sus empleados sobre la propia organización y el sistema de comunicación que existe a nivel interno, se puede ajustar o desarrollar e implementar un nuevo plan de comunicación interna acorde con las necesidades de la empresa. Es importante que el departamento de comunicación corporativa como el de recursos humanos debe contar con un responsable encargado de la comunicación interna. (Paul A. Argenti, 2014) 
Para el caso de recursos humanos debe ser la persona encargada de explicar asuntos como; beneficios que tiene cada colaborador además de la remuneración o la relativa a nuevas contrataciones, en tanto que la relativa al área de comunicación corporativa debe encargarse de la elaboración de mensajes que afectan a los empleados, como los cambios en los beneficios.

Algunas empresas optan por ubicar a los responsables de comunicar los temas relevantes a recursos humanos en el área de comunicación corporativa en aras de conseguir alinear la estrategia con la ejecución tanto del área de comunicación corporativa como de la del área de recursos humanos, lo cual permite garantizar que se cumplan los objetivos de cada departamento y se mantiene abierta la comunicación entre estas dos áreas funcionales tan importantes.

En empresas corporativas, lo ideal es que cada división comparta las mejoras prácticas de comunicación de mensajes relevantes a los empleados, teniendo en consideración las necesidades y particularidades de sus empleados, que, a su vez, afecta al contenido como al tono de la comunicación. Implementando en algunos casos, formas de comunicación interpersonal como en otra vía correo electrónico.

En otros casos, las empresas buscan apoyo externo para ejercer comunicación interna; cada vez se fortalece más la importancia de la comunicación interna, no es extraño que las empresas de consultoría en comunicación y relaciones públicas estén desarrollando permanentemente habilidades en esta área o que las compañías recurren con más frecuencia a utilizar sus servicios.

Los empleados como parte de los grupos de interés de la empresa deben estar actualizados sobre las noticias relativas al presente y futuro de la organización para que se sientan identificados, conectados y con capacidad de actuación. La probabilidad que un memorándum o que alguna otra comunicación se filtre al mundo exterior exige que los comunicadores internos siempre deban 
considerar la derivación e impacto de esos mensajes compartiéndolo con grupos de interés externos, incluidos periodistas e inversores.

\subsubsection{Principales canales de la Comunicación Interna}

En las empresas más pequeñas, la comunicación interna puede ser parte del trabajo de todos sus miembros, ya que el método ideal de comunicación con los empleados son las entrevistas personales o los encuentros cara a cara con pequeños grupos de empleados. Revisaremos algunos de los pasos claves para la implementación de un programa eficaz de comunicación interna, desde mecanismos personales de alcance individual hasta los programas que utilizan la tecnología para difundir mensajes de manera instantánea y masiva a un público amplio.

Los responsables de comunicación interna son los responsables de escoger la mejor combinación de canales de comunicación más adecuada para cada mensaje basándose en factores como requisitos de tiempo y las posibles reacciones de los empleados, esta combinación puede marcar la diferencia entre el éxito o fracaso de una iniciativa y puede afectar considerablemente el compromiso y motivación de los empleados.

\section{Comunicación ascendente y descendente}

Cuando está ausente la comunicación de abajo hacia arriba, las empresas son percibidas por la sociedad como organizaciones sin rostro, esto se genera por la dependencia excesiva de correos electrónicos formales. Es importante que los profesionales de comunicación interna faciliten a los jefes directos herramientas, información y apoyo continuo para presentar los mensajes a sus colaboradores directos. La comunicación interna eficaz debe fomentar un diálogo abierto en toda la organización y promover mecanismos de participación, a fin de que los empleados perciban a sus empresas más cercanas. 
Una buena práctica es mantener informados a los empleados mediante comités y reuniones informales trimestrales, fomentando el sentimiento de pertenencia. Conversaciones con la dirección sirven para promover el sentimiento de que los propios empleados sirven como catalizadores del cambio en la organización. Escuchar, respetar e interactuar con los trabajadores constituye la base para implementar un buen programa de comunicación interna eficaz. Es importante que los empleados aporten con su retroalimentación de forma permanente y da especial relevancia a que exista un flujo de comunicación de abajo-arriba. (Paul A. Argenti, 2014)

\section{Encuentros cara a cara}

Son reuniones presenciales con los directivos con grupos relativamente amplios colectivas e informales que deben ser frecuentes, por lo menos 1 vez por trimestre., que deben usarse como una oportunidad para la alta dirección para compartir información sobre los resultados de la compañía y el progreso en iniciativas clave, así como para demostrar su capacidad de respuesta la retroalimentación aportada por los empleados también es una oportunidad para plantear preguntas como un foro abierto. Si no es posible hacerlo de manera presencial se debe proponer mediante una conexión remota mediante videoconferencia.

Estos encuentros pueden servir para inspirar la creatividad, también permite llegar al mayor número de empleados. No obstante, también es importante reunirse con sus empleados en grupos más pequeños, son más eficaces cuando se desea solucionar problemas específicos. Las empresas cada vez son más conscientes de la utilidad y el valor de la comunicación cara a cara. 


\section{Comunicación online}

La intranet aportó un nuevo canal mediante el cual las empresas podían llegar a sus trabajadores en forma rápida y amplia cuando deseaban informarles sobre eventos o iniciativas importantes, es un buen canal para mantener informados a los empleados sobres sus beneficios.

Es importante utilizarlo con precaución si deseamos que sirva para mejorar la comunicación, y no para minar el impacto de los mensajes que emite la alta dirección, por ello las acciones de comunicación deben ser relevantes y atractivas para llegar en forma eficaz a los empleados.

Las redes sociales se convierten en una herramienta fundamental para la comunicación y para la articulación de la comunidad interna. A pesar de su importancia, los directivos deben evitar la tentación de trasladar toda su comunicación al mundo online, a menos que estén seguros de que todos los empleados utilizan ese medio. A pesar de ser atractivo este canal, no debería sustituir a la comunicación cara a cara entre los niveles directivos y empleados.

\section{Publicaciones dirigidas a los empleados}

Es el medio impreso, involucra a aquellos empleados que no cuentan con acceso al correo electrónico. Con frecuencia las publicaciones internas corporativas no son muy interesantes. Es importante que estas publicaciones conecten a los empleados con todo lo que sucede en su entorno laboral, debería contener acontecimientos importantes y logros alcanzados en todo el ámbito de la organización, además de ofrecerles una perspectiva sobre la dirección y estrategia general de la compañía. 
Otra forma de llegar a los empleados mediante publicaciones corporativas es enviarle a casa en vez de entregarlas en la oficina. Aunque esta distribución es más costosa, contribuye a introducir a la empresa en la familia y ser motivo de orgullo para el propio empleado y sus familiares. Cada publicación debe ser sincera y honesta sobre los asuntos que puedan afectar a los empleados.

El tono debe ser realista y auténtico ya que muchos empleados desconfían si se trata de propaganda más que de un verdadero acto de comunicación.

El tiempo que transcurra entre la comunicación interna y externa debe ser corto, ya que la compañía puede verse perjudicada si los empleados comparten información sensible accidentalmente con grupos de interés externo. Si los empleados reciben información crítica sobre la compañía de fuentes externas antes de recibir una comunicación interna, el impacto será negativo en su compromiso y confianza.

\section{Comunicar visualmente}

Se ha desarrollado muchas formas de comunicarse como webcasts hasta presentaciones multimedia, fomentando la interacción de los empleados. Muchas empresas cuentan con sus propios estudios de producción audiovisual administrados por expertos profesionales, estos sistemas sofisticados son el mejor mecanismo para producir contenidos propios y de especial relevancia para comunicarse con los empleados. En el caso que no lo tuviera, cuenta con proveedores externos que ofrecen este servicio.

Los webcasts pueden utilizarse de forma interactiva con blogs, vídeos en streaming, fotos o contenido en audio. Los empleados sin acceso al correo electrónico pueden reunirse en otros 
espacios, como en una cafetería para visionar estos webcasts en grupos, lo que crea una experiencia comunitaria y fomenta el diálogo entre ellos.

Este tipo de comunicación puede ofrecer un toque personal, haciendo realidad la visión de la compañía sin que sus líderes estén físicamente presentes. Si la producción se hace bien, puede ser una herramienta excelente para motivar a los empleados además de ser una historia visual de la organización que se podrá utilizar en el futuro.

\section{Sistema de comunicación informal}

El sistema informal de difusión o divulgación de la información dentro de la organización incluye desde conversaciones privadas entre dos personas hasta últimas anécdotas que se escuchan en la cafetería. Es importante que los directivos sepan aprovechar este tipo de comunicación, dado que existen estudios que revelan que casi la mitad de los empleados confían en este tipo de comunicación como fuente de información cuando se producen cambios importantes, y se consideran que los mensajes se difunden de manera más rápida y creíble mediante la red informal. Más del 90\% de empresas no tienen una política para gestionar la red de comunicación informal, los rumores que emergen a través de los sistemas no formales.

Cuanta mayor confianza, implicación y compromiso exista entre los empleados y la alta dirección, con menor frecuencia se recurrirá al sistema informal de información para expresar sus opiniones y escuchar a sus demás compañeros. (Paul A. Argenti, 2014).

\subsubsection{Proceso de Comunicación en cascada}

Un sistema de comunicación en cascada consiste en establecer una serie de reuniones entre los responsables de cada una de las divisiones de la empresa y sus equipos de trabajo. La 
particularidad de comunicación se basa en que las reuniones se hacen con una periodicidad definida y con carácter general para toda la organización. El protagonismo lo asumen las divisiones, la propia línea de mando es quien convoca y asume la dirección de la reunión. El responsable de la unidad de comunicación actúa como un facilitador de la reunión, dado que fija la periodicidad y aporta un mínimo común de información para toda la empresa y como un órgano de apoyo porque presta los servicios de comunicación que requiere la línea jerárquica. (Pinillos, 1996)

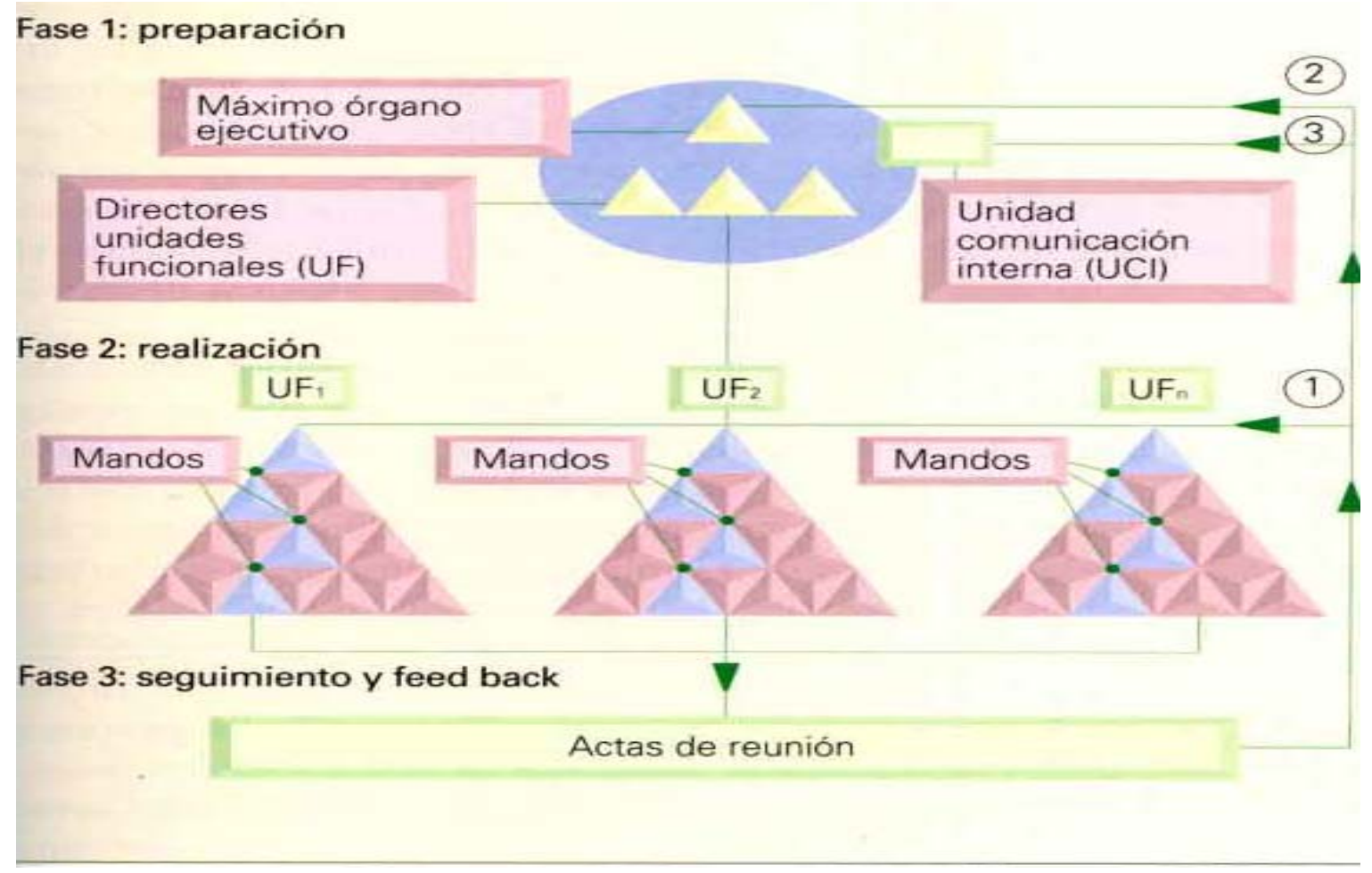

Figura 1. La infografía explica las fases de la comunicación en cascada. Adaptado de «Sistema de información en cascada», por Harvard Deusto Business Review, 1996. 


\subsubsection{El rol de la alta dirección en la comunicación interna}

La participación de los altos directivos en la comunicación interna es importante porque se trata de líderes que, encargados de transmitir la visión y la cultura corporativa, así como la estrategia global de la organización. Cada vez más directivos optan por ubicarse físicamente entre todos sus empleados, trabajando en una mesa de despacho estándar para fomentar la camaradería, implicar a los empleados de manera más directa y crear una sensación de responsabilidad y cultura compartida entre todos los empleados rompiendo la jerarquía y verticalidad en favor de una organización transversal.

Los responsables de comunicación interna deben trabajar con los gerentes de primera línea con el fin de ayudarles a elaborar mensajes que sean relevantes para los empleados que dependen directamente de ellos. Los altos directivos y responsables del área de comunicación, son las personas con mayor potencial para ayudar a transmitir a cada unidad de negocios y, sobre todo, relacionarlas con sus actividades cotidianas.

Para el caso de la empresa en estudio; considera que el líder es un agente activo de la comunicación y es el representante que encarna los valores y creencias de la organización. Por lo que un Líder debe:

- Usar la comunicación como una herramienta de gestión

- Tener en cuenta que el mensaje que transmite, puede tener efectos futuros

- Ser disciplinado a la hora de comunicar para minimizar la confusión, los rumores o sembrar ideas erróneas

- Tener presente que la actitud que comunica es más que las palabras, por lo tanto, debe ser cuidadoso con el contenido del mensaje y la forma. 
En conclusión, el Líder debe ser artífice de la comunicación clara, oportuna y transparente, donde los líderes formales son los llamados a mantener un flujo ordenado de información, útil para la toma de decisiones, para afianzar el alineamiento y la identificación con la organización. Se usa principalmente el canal de comunicación tipo cascada; el cual permite asegurar que los trabajadores de toda la organización dispongan de la misma información. 


\section{CAPÍTULO II: LAS RELACIONES SINDICALES EN UNA EMPRESA DE INDUSTRIAL EN EL PERÚ}

\subsection{El sector minero y PBI en el Perú}

La minería es uno de los motores de la economía del Perú, porque genera un valor agregado y aporta $10 \%$ al PBI del país. El Perú se ubica dentro de los primeros países productores de cobre, zinc, plata, y oro. Por otro lado, las regiones donde se realizan actividades extractivas se benefician con la transferencia de canon minero y la promoción de recursos para el desarrollo mediante el aporte directo de recursos. (Diario Oficial El Peruano, 2018)

Es importante indicar que la minería metálica, desde el año pasado ha experimentado un período de recuperación y este año está en un mejor momento, debido al incremento de precios en los minerales en los mercados internacionales.

Según manifiesta la Sociedad Nacional de Minería, Petróleo y Energía, el impacto de un incremento en el $15 \%$ de las exportaciones mineras significan un aumento de $2.1 \%$ del PBI, que se sustenta en:

- La creación de nuevos empleos que representan $0.9 \%$ de la población económicamente activa,

- Incremento en ingresos por impuestos en el sector público en 9,000 millones de soles y el valor de la deuda pública se reduciría.

- Sector externo, ganancias de divisas, reducción del déficit en cuenta corriente y una ligera caída en tipo de cambio. 
- Incremento en la inversión privada, dada la importancia que tiene el sector minero en el ritmo de crecimiento en los últimos diez años en el Perú.

La Constitución Política establece en su artículo 22, el derecho al trabajo y en el inciso 15 del artículo 2 de la Constitución, la libertad de trabajo en alusión al atributo para elegir voluntariamente la actividad ocupacional o profesional que prefiera desempeñar, disfrutando de sus beneficios económicos, con la consecuente satisfacción que produzca, considerando que la verdadera dignidad del trabajador se sustenta en el ser sujeto y autor del trabajo y, en consecuencia, genuino fin de todo proceso productivo, así como la prerrogativa de cambiarla o de cesar de ella, la referida facultad debe ser ejercida con los límites que la ley prevea para dicho efecto.

En este contexto se tiene a la minería como una actividad de alto riesgo para la seguridad y salud de los trabajadores por los procesos tecnológicos que se realizan, como por las características geográficas y el medio ambiente en el que se ubican los emplazamientos de los yacimientos, los modos operativos en que se planifica y ejecuta el trabajo, en el desempeño de esta actividad se advierte un alto esfuerzo físico, así como las condiciones de salud de los trabajadores mineros ${ }^{1}$.

La constitución reconoce la libertad sindical en su artículo 28, inciso 1) como el derecho constitucional con contenido esencial un aspecto orgánico, así como un aspecto funcional.

El primero alude a la facultad de toda persona de constituir organizaciones con el propósito de defender sus intereses gremiales. El segundo se refiere a la facultad de afiliarse a este tipo de

\footnotetext{
${ }^{1}$ En el sector minero, se han reconocido alrededor de treinta enfermedades profesionales, por ello implica brindar una adecuada protección al trabajador minero y la dotación que permitan reducir los riesgos propios de la actividad que desempeña.
} 
organizaciones. A su vez, implica la protección del trabajador sindicado a no ser objeto de actos que perjudiquen sus derechos y tuvieran como motivación real su condición de afiliado de un sindicato.

Asimismo, la negociación colectiva es el principal instrumento para la armonización de los intereses contradictorios de las relaciones laborales entre el empleador y trabajador. La Constitución impone al Estado la obligación del deber de fomentar la negociación colectiva y promover las formas de solución pacífica de los conflictos laborales.

El derecho a la negociación colectiva es un derecho fundamental de carácter colectivo, y de configuración legal, por virtud de este se reconoce a las organizaciones de trabajadores un haz de facultades para regular conjuntamente sus intereses en el ámbito de las relaciones de trabajo.

La negociación colectiva se encuentra regulada en el Texto Único del Decreto Ley NO. 25593, Ley de Relaciones Colectivas de Trabajo y Ley No. 27912, que establece, entre otros temas fundamentales, el contenido de la negociación colectiva, el mecanismo de negociación, la representación de los trabajadores, asimismo, se dispone sobre el procedimiento de conciliación, la mediación, el laudo y la intervención de la autoridad del trabajo en caso de huelga (arbitraje obligatorio), del mismo modo, se establecen las condiciones para la declaración de huelga, se definen los servicios públicos esenciales y las condiciones de declaración de ilegalidad de una huelga el contenido de la negociación colectiva, el mecanismo de negociación, la representación de los trabajadores. 


\subsection{Marco Legal de pago de Utilidades}

La participación de utilidades es un derecho reconocido en el artículo 29 de la Constitución Política del Perú, al cual acceden las empresas que generan renta de tercera categoría y tienen derecho todos los trabajadores. (Ministerio de Trabajo y Promoción del Empleo, 2018)

Las empresas están obligados a distribuir utilidades, siempre y cuando las empresas:

- Cuenten con más de 20 trabajadores

- Sean generadores de renta de tercera categoría, según la Ley de Impuesto a la Renta.

- Que, en un determinado año hayan producido una renta anual antes de impuestos, sobre la cual se determinan las utilidades laborales.

El pago se realiza dependiendo la industria a la cual pertenece la empresa

- $\quad$ Sector pesquero $\quad 10 \%$

- Sector Telecomunicaciones $\quad 10 \%$

- Sector industrial $\quad 10 \%$

- Sector Minero $\quad 8 \%$

- Comercio y restaurantes $\quad 8 \%$

- Otras actividades $\quad 5 \%$

Las utilidades se pagan dentro de los 30 días después de haber presentado la declaración jurada a la SUNAT. Si la empresa no paga dentro de este plazo las utilidades generaran intereses a favor del trabajador y además a la empresa se le impondrá una multa, dependiendo el tamaño de la misma. 


\subsection{Huelgas como medidas de presión en el Perú}

De acuerdo al artículo 28 de la Constitución Política del Perú, el Estado además de reconocer los derechos sindicales y negociación colectiva de los trabajadores, también regula el derecho de huelga para que se ejerza en armonía con el interés social: Señala sus excepciones y limitaciones.

La huelga es por definición la suspensión colectiva del trabajo acordada mayormente y realizada en forma voluntaria y pacífica por los trabajadores, con abandono del centro de trabajo.

Es importante mencionar que el ejercicio del derecho de huelga supone haber agotado previamente la negociación directa entre las partes respecto a la materia controvertida. (Ministerio de Trabajo y Promoción del Empleo, 2018)

Las principales causas de la mayoría de las huelgas sindicales son por incumplimiento de normas legales y/o convencionales, amenazas de despidos, y otros motivos como:

- Homologación salarial, pago de utilidades, beneficios sociales, igualdad.

- Condiciones de trabajo, seguridad y salud en el trabajo

- Contratación a plazo fijo

- Reposición de trabajadores y sanciones

- Procesos de cambio (traslados, asensos y funciones)

En el Perú en el último año, los sectores económicos que registran un mayor número de pérdida de horas-hombre son: Administración Pública y Defensa: 1'843,538 h/h, seguida del sector explotación de minas y canteras 991,464 h/h e industrias manufactureras: 89,880h/h. (MTPE/oficina de estadística, 2017) 
Cuando las huelgas se dan dentro del marco legal, las empresas y representantes legales, se exponen a:

- Denuncias penales

- Deterioro de la imagen de la empresa y clima laboral

- Reposiciones e indemnizaciones

- Multas (hasta 300UIT)

La huelga se da por terminada, cuando:

- Por acuerdo de las partes en el conflicto.

- Por decisión de los trabajadores.

- Por haberse solucionado el pliego de reclamos mediante el pronunciamiento de la Autoridad Administrativa de trabajo.

- Por ser declarada ilegal, cuando no cumple con los causales para llevar a cabo esta medida de fuerza.

\subsection{Contexto Sindical en una empresa industrial en el Perú}

El sindicato de la empresa estaba conformado por trabajadores obreros, los mismos que representaban a más de la mitad del total de la planilla de la empresa. Era un sindicato histórico con más de 30 años de existencia, dentro del cual contaba con experimentados dirigentes sindicales. Dada la historia y antigüedad del sindicato, éste era de corte confrontacional y poco tendiente al diálogo, justamente los dirigentes que realizarían la negociación, priorizaban las 
medidas de fuerza para ejercer un dote de poder y así poder conseguir que la empresa atienda sus requerimientos.

Contar con sindicatos dentro de las empresas forma parte del relacionamiento laboral que existe en las dos partes de toda relación de trabajo, debe ser política de la empresa establecer los lineamientos y estrategia efectiva de manejar los conflictos con sus trabajadores sindicalizados, el manejo del conflicto basado en la empatía y el diálogo es lo que resulta generalmente beneficioso en la resolución de los conflictos laborales, ya que ambas partes tienen la oportunidad de conseguir la absolución a sus requerimientos y entender los contextos y realidades.

La empresa por su lado, era un empresa del rubro industrial, con sede en Perú, con altos estándares de producción, seguridad y gestión del talento; que tenía dentro de su política de relaciones laborales gestionar sus relaciones sindicales mediante sus valores del respeto y diálogo; creyendo que la comunicación clara, oportuna y transparente con sus trabajadores era la clave para la gestión de conflictos, incluso para sustentar las razones por las cuales en ciertas ocasiones no era posible el atendimiento de los requerimientos de sus trabajadores afiliados, contexto en el que se envuelve la presente tesis.

El periodo de análisis se remonta entre los meses de enero y marzo del año 2018, cuando en una importante empresa industrial en el Perú correspondía tratar con su sindicato, el tema del reparto de utilidades del año anterior. El primer trimestre del año 2018, se tornaba crítico ya que en el ejercicio 2017 la empresa había generado utilidades luego de varios años en los que no correspondió el reparto de este concepto, considerando que, durante estos años anteriores, la empresa venía otorgando una bonificación extraordinaria para compensar anualmente el no reparto de utilidades. 
Cabe indicar, que desde el año 2012 al 2016, la empresa a causa del no pago de utilidades otorgó a todos sus trabajadores un bono en compensación económica.

Tanto el sindicato como la empresa pactaron colectivamente que para el periodo que corresponda el pago de las utilidades conforme a ley, cesaría el pago de la bonificación extraordinaria. Sin embargo, era sabido que el sindicato pretendía requerir a la empresa que se mantenga el pago de este bono extraordinario, y a su vez, que se realice el pago de utilidades de acuerdo a ley por el periodo 2017, no reconociendo con ello, el acuerdo que habían arribado con la empresa de manera anticipada. Bajo este escenario se daría inicio al proceso de una nueva negociación colectiva por el cual el sindicato y la empresa tratarían de llegar a un acuerdo sobre el pago de la bonificación extraordinaria.

\subsubsection{Estrategia de la negociación sindical en el período 2018}

Conocida la pretensión del sindicato, la Gerencia de Recursos Humanos diseñó la estrategia de negociación colectiva, la misma que fue discutida y validada con la Gerencia General. Esta fue basada en las siguientes premisas:

o Mantener un adecuado clima laboral

- Asegurar la estabilidad operacional

o Establecer una comunicación directa con el sindicato

- Cumplir los acuerdos previos

o Cumplir la legislación laboral peruana 


\section{Posición de la empresa}

Luego de las validaciones internas dentro de la empresa, la estrategia para la negociación sindical fue cumplir con el pago de las utilidades de acuerdo a ley para el periodo 2017, y negociar un pago considerable por bonificación extraordinaria.

La empresa había reunido a ciertos puestos importantes para conformar una comisión de negociación. En ella estaban el Gerente de recursos humanos, Jefe de relaciones sindicales, Jefes y Gerentes, así como las Gerencias de operaciones.

\section{Posición del sindicato}

Por su parte el sindicato tenía como estrategia requerir el pago de utilidades conforme a ley, más el pago de la totalidad del bono extraordinario ascendente a cuatro salarios mensuales para cada trabajador sindicalizado.

La comisión de negociación del sindicato estaba conformada por diez dirigentes y tres asesores legales. En la reunión participaban trece personas que representaban ocho al sindicato versus cinco personas que representaban a la empresa. Con la comisión de sindicato, las reuniones eran de dos a tres veces por semana con horario libre, podía durar dos horas como el día entero.

Las partes, empresa - sindicato, marcaron las señaladas posiciones y así iniciaron las reuniones de trato directo con el sindicato, las mismas que desde el inicio fueron reuniones cargadas de fricción por parte del sindicato, dado que desde el inicio de las conversaciones 
plantearon a la empresa, que, de no atender a sus requerimientos, materializarían una huelga general indefinida. ${ }^{2}$

Ante dicho escenario, la empresa intentó dialogar con el sindicato sosteniendo que debían respetarse los acuerdos suscritos entre las partes de buena fe, y que para el año 2017 ya no correspondía el bono extraordinario, toda vez, que se habían generado utilidades; y que en todo caso si el sindicato deseaba solicitar el pago de un beneficio extraordinario, la empresa no podría atender dicha solicitud bajo un contexto de presión como era la amenaza de una huelga.

Durante todo el proceso de negociación se realizaron con la presencia de las comisiones negociadoras de empresa y sindicato, reuniones técnicas de los resultados de los Estados Financieros de la empresa, con fin de que se inicie el proceso de una manera clara y transparente. Deduciéndose de dicha explicación claramente que la empresa por el periodo 2017, sí iba a brindar pago de utilidades para sus colaboradores, haciendo incluso algunas proyecciones de cuántos sueldos representaría para los operadores.

La empresa y sindicato sostuvieron reuniones directas cara a cara, emitiéndose también documentos por ambas partes, como por ejemplo tres comunicados difundidos a todo el personal, en los cuales el sindicato expuso informaciones tendenciosas y falsas pretendiendo dañar la imagen de funcionarios y de la empresa. Ésta por su parte envió varias comunicaciones formales al sindicato solicitándoles más prudencia en sus mensajes e informaciones.

Asimismo, el sindicato no prestó atención a estas comunicaciones y continuó emitiendo comunicaciones con informaciones falsas, pretendiendo incluir otros temas para causar confusión

\footnotetext{
${ }^{2}$ Ver Anexo I: Nota de Prensa Sindicato
} 
entre los trabajadores. Estas publicaciones se difundieron en las redes sociales de los involucrados del sindicato e incluso de los dirigentes sindicales. ${ }^{3}$

También, el sindicato publicó en prensa mensajes con los cuales pretendía dañar la imagen de la empresa, así como enviaron cartas al gerente general, por supuesta afectación al derecho de opinión, libertad sindical, utilidades, contaminación ambiental, entre otros. ${ }^{4}$

Al analizar el comportamiento del sindicato, los representantes se mostraron siempre en contra de la empresa, exigiendo lo que creían les correspondía y más. Asimismo, al mostrar una posición confrontacional y radical, era difícil mantener una comunicación saludable. Para la empresa era muy importante mantener un clima laboral adecuado y asegurar la estabilidad laboral de sus trabajadores.

En las reuniones que se realizaban, los asistentes por parte del sindicato se posicionaban de manera agresiva queriendo obtener lo que plantearon en primer lugar sin tener algún sustento. Las reuniones podían durar horas y era un ambiente cargado, llenas de fricción y sin ceder sobre la posición que tenían. La empresa trató muchas veces de dialogar, pero no podían negociar en un ambiente bajo presión y amenazas. Sus propuestas no fueron escuchadas.

Los comunicados que recibían los operarios, los anuncios en redes sociales, prensa o información de pasillos, hizo que la negociación fuese más difícil. Existió mucha información falsa y ocasionó confusión entre los trabajadores. Los anuncios en redes sociales eran agresivos, sobre la empresa, queriendo afectar su reputación y la de los gerentes. ${ }^{5}$

\footnotetext{
${ }^{3}$ Ver Anexo II: Estatus Sindical

${ }^{4}$ Ver Anexo III: Sanciones Sindicato

${ }^{5}$ Ver Anexo IV: Monitoreo Redes Sociales Sindicato
} 
Este fue el contexto en el que se desarrolló el proceso de negociación sindical, dentro de la cual, los jefes directos de los trabajadores sindicalizados serían los portavoces y protagonistas de la comunicación de los mensajes de la empresa. Los jefes directos de los trabajadores sindicalizados fueron considerados los líderes y representantes de la empresa durante todo el desarrollo del proceso de negociación sindical.

Una vez definida la estrategia de negociación de la empresa, empezó el trabajo para diseñar la estrategia de comunicación interna, avizorando que el sindicato plantearía una huelga como medida de presión para exigir el pago del bono extraordinario, pese a que ya habían pactado colectivamente con la empresa que no correspondería una vez que se generen utilidades, como lo era en el año 2017. 


\section{CAPÍTULO III: ESTRATEGIA DE LA COMUNICACIÓN EN CASCADA DENTRO DEL PROCESO DE NEGOCIACIÓN SINDICAL}

La empresa se encontraba en una situación en la cual la información que se brindaba, no bajaba a todos los niveles o no llegaba de manera oportuna a todos los trabajadores. Se corría el riesgo de estar mal informados, ya que la comunicación se recibía por otros canales de manera no oficial y los líderes no comunicaban los mensajes de manera efectiva.

Es por ello se propuso a la empresa con meses de anterioridad, iniciar un proceso de entrenamiento de todos sus jefes y supervisores, con la finalidad de desarrollar y fortalecer la comunicación a todo nivel, sobre todo asegurar que la comunicación en cascada se realice de una manera clara, oportuna y transparente, preparándolos para que estén mejor posicionados al inicio del proceso de negociación colectiva que se iniciaría a causa del pago de utilidades. Los entrenamientos fueron realizados entre los meses de noviembre y diciembre del año 2017.

Lo que se quería lograr era el diseño de una estrategia de comunicación en cascada donde los líderes sean los protagonistas de la difusión de los mensajes dentro de la negociación con el sindicato. Era importante fortalecer las habilidades de comunicación del liderazgo. Asimismo, asegurar que la información relevante y sensible para la organización, sea comunicada por cada líder a sus equipos. Para ello se propuso la estrategia de comunicación, la misma que debía empezar a formar parte de la rutina y la cultura organizacional, para lograr una mejor comunicación, con información precisa y oportuna. 
Esta estrategia tenía que desarrollarse dentro del proceso de negociación que se realizaría dentro del primer trimestre del año 2018; se planteó la estrategia de comunicación interna con el objetivo de posicionar a los líderes en un momento de crisis sindical como legítimos representantes de la empresa, tender puentes de comunicación con sus operadores sindicalizados, emitir mensajes de la empresa en forma transparente, oportuna y clara; y que la comunicación organizacional sea contundente y estructurada.

Era muy importante empoderar a todos los líderes y hacerles tomar conciencia sobre la importancia de su rol, ya que serían los responsables de llevar los mensajes de la empresa a toda la base sindicalizada. Debían dar el máximo soporte en el ámbito comunicacional dentro del proceso de negociación, considerando que la empresa no atendería la totalidad de las pretensiones de la organización sindical, pero, sobre todo, lo relevante también era que el liderazgo implemente la comunicación en cascada de manera efectiva, y dentro de la negociación los trabajadores cuenten con información oficial y oportuna, pero por parte de la empresa.

La propuesta que se ofreció a la empresa, consistió en implementar un flujo de comunicación en cascada en la cual partía desde la identificación de la necesidad de comunicar ciertos mensajes en contextos específicos, esta identificación de los mensajes partía de las gerencias, una vez dicha identificación la gerencia tenía que coordinar con el área de comunicación para que se definan los mensajes claves y el contenido de los mismos a través de un formato diseñado para este fin, así como los plazos y momentos en los cuáles los líderes debían realizar la comunicación en cascada.

Continuando con el flujo abajo presentado, el área de comunicaciones convocaba a todas las gerencias conformadas por sus respectivos gerentes, jefes y supervisores, para que de manera presencial (cara a cara) el gerente de recursos humanos difunda los mensajes claves que luego 
debían trasladar los líderes a cada uno de sus equipos conformados por operadores, la mayoría sindicalizados. Posteriormente a esta reunión de alineamiento, y dentro del plazo otorgado, los líderes iniciaban el flujo de comunicación; finalmente nuevamente la intervención del área de comunicación para realizar la medición de los mensajes difundidos y encontrar oportunidades de mejora, resultados que se mostraban periódicamente en las reuniones de gerencia general.

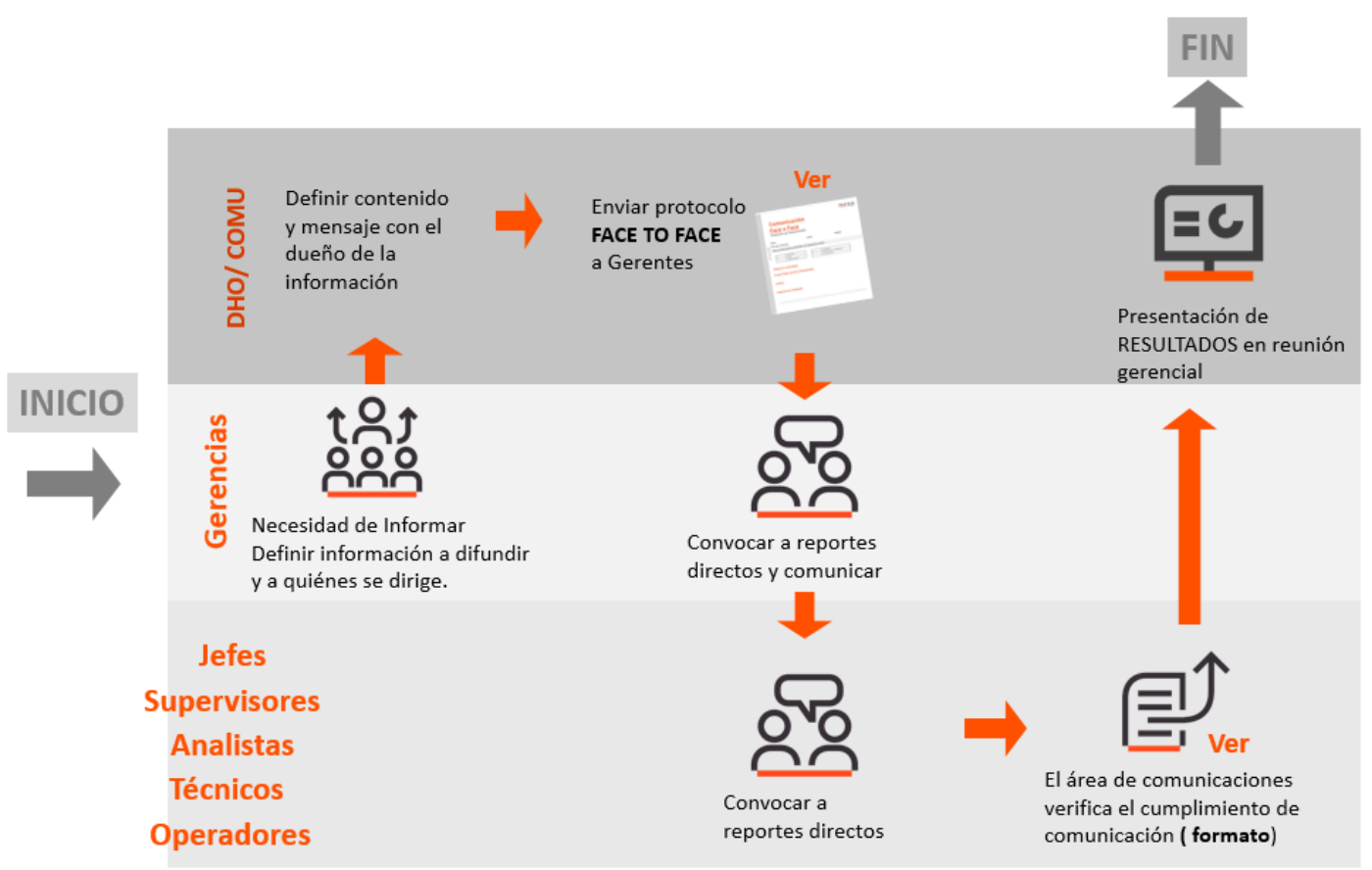

Figura 2. Flujo muestra la comunicación de los líderes. Adaptado de «Flujo de comunicación en cascada» por elaboración propia, 2018

La estrategia de comunicación en cascada propuesta para el proceso de negociación sindical, se basó en una serie de premisas:

o Empoderamiento de los jefes directos de los trabajadores sindicalizados, quienes se convertirían en los portavoces de los mensajes de la empresa, a quienes en todo momento los identificaron como el liderazgo de la empresa. 
Toda vez que cuando los mensajes difundidos sean trasladados a los trabajadores sindicalizados, ellos debían percibir un liderazgo fuerte y en bloque, para así generar una percepción creíble y positiva, no confrontacional y con apertura al diálogo.

o Implementación del flujo de comunicación que debía liderar el área de comunicación de la empresa y la gerencia de recursos humanos, de quienes partía la metodología de la comunicación en cascada e impartiendo los mensajes claves. La gerencia de recursos humanos debía asegurar que la comunicación sea efectiva y para ello debía dar el soporte en que el flujo se cumpla, identificando correctamente los mensajes claves, asegurando que los mensajes sean redactados de manera clara y sencilla, monitoreando que los jefes realicen la comunicación en cascada correctamente identificando mejoras.

o Llegar al personal sindicalizado con mensajes influyentes generando una reflexión individual del cumplimiento de los acuerdos. Durante el proceso de negociación de utilidades y bono, la comunicación en cascada debía producir no solo información oficial y objetiva, sino que también debía producir en los trabajadores una reflexión para la toma de decisión de acatar la huelga que el sindicato iba a proponer, o en todo caso, de materializarse la huelga, a través de la comunicación en cascada los líderes debían comunicar a sus trabajadores los impactos de la huelga, y reforzar el diálogo como mecanismo de solución de conflictos. 
Es así que la estrategia de comunicación en cascada consideró los siguientes canales de comunicación:

\section{Reuniones presenciales de alineamiento y actualización con los jefes directos del personal sindicalizado:}

La estrategia de comunicación se puso en marcha con la primera reunión de alineamiento a la cual asistió todo el equipo gerencial de la empresa como representantes máximos de la organización y sus reportes directos que eran los jefes del personal sindicalizado. Esta apertura de la estrategia de comunicación fue dirigida por el gerente de recursos humanos de la empresa, el cual comunicó la estrategia de negociación y la posición que mantendría la empresa durante todo el proceso de negociación sindical.

En efecto la posición de la empresa sería: cumplir con el pago de las utilidades de acuerdo a como lo determine la ley, y dejar de otorgar la bonificación extraordinaria que años anteriores se otorgaba en compensación por el no pago de utilidades.

En estas reuniones de alineamiento con el liderazgo, se emitieron los mensajes claves iniciales que los jefes debían comunicar a todo su personal sindicalizado, de esta manera se sostuvieron reuniones de alineamiento semanales, a su vez se actualizaban a los líderes del avance del proceso.

Durante todo el proceso de negociación se realizaron diez reuniones de alineamiento con los jefes, en cada una de ellas se impartían los mensajes a ser comunicados, el proceso de 
negociación que se desarrolló desde enero a marzo de 2018, considerando incluso la materialización de la huelga indefinida ocurrida en la primera semana de marzo. ${ }^{6}$

Además de impartir los mensajes fuerza a ser trasladados por los líderes en el curso de la semana, también se absolvían dudas y consultas de los jefes, así como se monitoreaba como venían percibiendo los trabajadores los mensajes dados por el liderazgo de tal forma que contribuyeran en la mesa de negociación con la dirigencia sindical. ${ }^{7}$

El efecto de estas reuniones de alineamiento generaba que en determinados momentos todo el liderazgo de la empresa transmitiera un mismo mensaje y posición de la empresa, además que contaban con información oficial y de primera mano de cómo venía desarrollándose la negociación. Tenían como objetivo trasladar confianza y mensajes claros y claves, ya que ellos eran los replicadores y representantes de la empresa en las respectivas áreas, eran ellos quienes debían percibirse seguros y al tanto de todo lo que venía aconteciendo dentro del proceso de negociación.

Cabe mencionar, que unos de los efectos que también causaron estas reuniones cara a cara de alineamiento, es que el clima entre el liderazgo mejoró y fue reforzado el respaldo que la empresa otorgaba a todos sus jefes y supervisores, ya que al trasladar información actual y compartir de cómo se desarrollaba la negociación sindical en tiempo real, permitió que todo el liderazgo fueran partícipes de uno de los procesos de mayor impacto que tenía la empresa, con ello se demostraba que los líderes estaban involucrados en toda la gestión de la empresa frente al sindicato, mostraban un posicionamiento fortalecido.

\footnotetext{
${ }^{6}$ Ver Anexo V: Reuniones de alineamiento con los líderes

${ }^{7}$ Ver Anexo VI: Mensajes Fuerza
} 
Estandarización de mensajes fuerzas a ser trasladados a todo el personal de la empresa a cargo de los jefes

Luego de las reuniones presenciales de alineamiento con los líderes, el área de comunicaciones de la empresa, enviaba vía correo electrónico un resumen de lo tratado en dichas reuniones, especificando los mensajes fuerza a ser transmitidos por los jefes utilizando el formato de comunicación en cascada, así como las principales preguntas y respuestas que pudieran generarse por parte del personal sindicalizado, con el objetivo de que los líderes estén preparados y posicionados con respuestas claras, oportunas y transparentes.

Se diseñó el siguiente formato de comunicación en cascada, con la finalidad de facilitar y uniformizar los mensajes a ser trasladados verbalmente por lo líderes, así como también para resumir la información relevante que eran tratadas dentro de las reuniones de alineamiento presenciales dirigido por el gerente de recursos humano. 
Lo que se pretendía también con el formato, era reforzar lo que iban a hablar los jefes con sus operadores, en el sentido, que todos los líderes tengan una pauta en sus discursos y perseguir que estén estandarizados y fuera considerado como un protocolo de comunicación.

\section{Comunicación Cara a Cara}

Protocolo de Comunicación
Tema:
Fecha:
Unidad:

Área que comunica:

Este mensaje debe ser difundido a los siguientes niveles:

\begin{tabular}{|l|l|}
\hline & Gerentes \\
\hline & Jefes \\
\hline & Supervisores \\
\hline
\end{tabular}

\begin{tabular}{|l|l|}
\hline & Analistas \\
\hline & Operadores y Técnicos \\
\hline & Practicantes \\
\hline
\end{tabular}

MENSAJE A DIFUNDIR:

PUNTOS FOCALES :

Los tres puntos más importantes de la información, que deben quedar muy claros.

DUDAS:

Colocar con quién dirigirse para consultar dudas

PLAZO PARA QUE SE COMUNICADO:

PREGUNTAS Y RESPUESTAS

Figura 3. Formato muestra el protocolo de comunicación. Adaptado de «Formato de comunicación en cascada» por elaboración propia, 2018

Los criterios contemplados en este formato de comunicación en cascada, fueron:

- Identificación del público a quienes tenían que ser dirigidos los mensajes: operadores, técnicos, analistas, entre otros. 
- Puntos focales de los mensajes a difundir, los mensajes claves que no podrían dejar de mencionarlos y sobre los cuáles debían poner mayor énfasis.

- Indicar quienes serían las personas de contacto en caso algún trabajador desee mayor información o quisiera aclarar algunas dudas.

- El plazo que tenían los líderes para cumplir con trasladar los mensajes claves contenidos en el formato.

- Preguntas y respuestas probables para que los líderes puedan tener un respaldo y estandarizar las respuestas hacia los trabajadores.

- Recomendaciones para los líderes, pautas generales de una buena comunicación en cascada, como, por ejemplo, hacer preguntas al público si está entendiendo lo comunicado, utilizar un tono de voz amables, entre otros.

Esta herramienta de comunicación fue utilizada durante todo el proceso de negociación colectiva, y permitió a los jefes tener una estructura y pauta en lo que la empresa requería comuniquen, todos los mensajes claves durante la negociación fueron formalizados en este documento, el mismo que era enviado por el área de comunicaciones de la empresa a todo el liderazgo, quienes ya previamente habían asistido a la reunión de alineamiento.

Dentro de los mensajes claves por parte de la empresa durante todo el proceso de negociación, se difundieron de manera verbal y a través de la comunicación en cascada que realizaban los líderes hacia sus operadores. Principalmente estos mensajes eran difundidos cara a cara luego de la charla de seguridad a la apertura de la jornada laboral, si el líder no realizaba los mensajes en este tiempo, tenía el lineamiento que debía hacer un alto a las labores durante el día y cumplir con trasladar el mensaje clave según el desarrollo de la negociación. Generalmente la difusión de estos mensajes 
era reforzada durante la semana a fin de que todos los trabajadores tengan la oportunidad de contar con la información de la negociación colectiva.

A continuación, se detallan los principales mensajes difundidos de manera verbal a través de la comunicación en cascada;

\section{Enero 2018:}

- Puentes de diálogo: la empresa dio inició a la negociación colectiva priorizando la comunicación clara y transparente con todos sus trabajadores, siendo objetivo que dicho proceso se desarrolle dentro de un ambiente de buena fe, respeto por los acuerdos tomados dentro del cumplimiento de la ley".

- Confianza en sus trabajadores: "Estando en el inicio de la negociación con el sindicato, la empresa confía en que la actitud de sus trabajadores será de responsabilidad y buena fe, en el cumplimiento de sus labores y concentración de sus tareas, identificando riesgo en el trabajo a fin de prevenir accidentes; la negociación sindical no debe ser motivo de distracción, más bien, aguardar con expectativa los resultados a los que llegarán ambas comisiones negociadoras".

- Posición de la empresa: "Desde el inicio de la negociación, la empresa manifiesta a todos sus trabajadores, que será firme en requerir al sindicato que se cumplan los acuerdos previos respecto al tema de pago de utilidades, como todos sabemos, para el año 2018 no se pagarán los bonos extraordinarios, ya que los trabajadores recibirán el reparto de utilidades, de acuerdo a nuestros valores, debemos respetar los acuerdos suscritos."

\footnotetext{
${ }^{8}$ Ver anexo VII: Protocolo de comunicación enero 2018
} 


\section{Febrero 2018:}

- Sobre el reparto de utilidades. "La empresa brindará al sindicato información referente a los Estados Financieros 2017, de manera técnica y transparente”.

- Cumplimento de la ley: "Si corresponde pago de utilidades por el año 2017, por ello la empresa dentro del plazo de ley pagará a todos sus trabajadores sin excepción, la empresa cumple la ley."

- Medidas de presión: "No es parte de la cultura de la empresa, llegar acuerdos bajo medidas de presión, no forma parte de sus principios y valores. Respecto de la comunicación de huelga, la empresa rechaza todo acto que tenga por finalidad ejercer presión y crear un clima de caos y de inestabilidad. Llamamos a todos los trabajadores a una reflexión"

- Cumplimiento de Acuerdos: "Las relaciones entre la empresa y sindicato deben basarse en la buena fe, por ello el cumplimiento y respeto por los acuerdos deben ser la base de su relacionamiento".

- Fundamentos de la huelga: la huelga ha sido declarada incluso antes de que la empresa brindará información sobre los resultados financieros del 2017, sin que el sindicato aún tome conocimiento si procede o no el pago de utilidades y sin tener ninguna reunión para tratar la solicitud de bono. Creemos firmemente que la huelga no tiene sustento legal y será declarada improcedencia para luego conseguir su ilegalidad. Hacemos un llamado a la calma, la empresa acatará lo que la autoridad dictamine".

- Declaración de Improcedencia de la Huelga: "Todos los trabajadores deben conocer que el Ministerio de Trabajo acaba de declarar improcedente la huelga, lo cual tendrá 
repercusiones legales si se continúa con la paralización, la empresa exhorta a todos sus trabajadores a reanudad sus labores y no generar un clima de inestabilidad." 9

\section{Marzo 2018:}

- Labores indispensables: "Se anima a todos los trabajadores a ser respetuosos de sus turnos de trabajo, ya que, si bien la empresa respeta la huelga de sus trabajadores, existe un grupo de trabajadores que, si deben asistir a laborar por encontrarse dentro de la relación de labores indispensables, ya que la ley nos faculta a preservar aquellos puestos de trabajo que son indispensables para no paralizar totalmente la producción, revisar los paneles colocados en la puerta de ingreso a la empresa".

- La empresa vela por la seguridad: "La empresa está alerta para brindar condiciones de seguridad y resguardo a sus trabajadores que individualmente ha decidido no acatar la huelga, pueden sentirse respaldados que la empresa será firmé en tomar medidas contra toda persona que atente con nuestras normas internas y actúe fuera del marco de la ley".

- Libertad en tomar decisiones: Respetamos las decisiones colectivas e individuales de todos nuestros trabajadores, exhortamos que estas decisiones sean también respetadas entre compañeros de trabajo, independientemente sean o no sindicalizados, el derecho de huelga debe ser acatado de manera libre y consciente, si existe la voluntad de algún trabajador de retornar a laborar, es libre de hacerlo, si su decisión es seguir acatando la huelga, también se respeta".

\footnotetext{
${ }^{9}$ Ver anexo VIII: Protocolo de comunicación febrero 2018
} 
- Declaración de la ilegalidad: "A todos nuestros trabajadores comunicamos que la autoridad de trabajo ha declarado la ilegalidad de la huelga, por ello solicitamos sean reanudadas las labores en sus horarios habituales, esta ilegalidad demuestra que la medida de presión no tiene ningún fundamente válido para su realización, animamos a seguir adelante con nuestras labores".

- Puertas abiertas: "De acuerdo a nuestra política de puertas abiertas, manifestamos a todos nuestros trabajadores a reanudar nuestras labores con el objetivo de reestablecer nuestro buen relacionamiento y seguir cumpliendo con todas nuestras metas y objetivos, la empresa mantiene un espíritu de aprendizaje y optimismo que este año cumpliremos en equipo todas nuestras metas, ¡a seguir adelante!"10

Mientras se realizaban la difusión de estos mensajes claves, los líderes tenían la libertad de acudir directamente al área de comunicaciones de la empresa, en caso surgiera algún acontecimiento no mapeado en la reunión de alineamiento o del contenido del correo electrónico, con el fin de obtener asesoramiento al tratar algún tema o conversación difícil. El área de comunicaciones quien tenía contacto directo e inmediato con la comisión negociadora rápidamente podía ayudar para aclarar los mensajes, o activar un nuevo alineamiento con las jefaturas. De esta manera se daban todas las facilidades para que el flujo de la comunicación sea muy dinámico siempre con el objetivo de respaldar al liderazgo como portavoz oficial de la empresa.

\footnotetext{
${ }^{10}$ Ver anexo IX: Protocolo de comunicación marzo 2018
} 


\section{Emisión de comunicados escritos por parte de la empresa dirigidos a todos sus trabajadores.}

En los momentos que la empresa consideraba claves dentro del proceso de negociación, o deseaba marcar un precedente de su posición, emitía además comunicados escritos que eran repartidos en físico a todo el personal de la empresa en los horarios de ingreso o salida del personal. El área de comunicaciones redactaba estos comunicados alineados con la comisión negociadora y validaba la gerencia general, a su vez se aseguraba que el cien por ciento de los trabajadores lo hayan recibido.

Dentro la propuesta de comunicación en cascada, se consideró la evaluación de la efectividad de dicha comunicación. Como ya hemos indicado precedentemente el liderazgo ya contaba con una serie de entrenamientos sobre precisamente el rol del líder comunicador, habiendo recibido técnicas de comunicación con la finalidad de que se encuentre preparados al momento de trasladar las informaciones a su personal sindicalizado, con el fin de desarrollar sus habilidades como comunicadores.

Para monitorear la medición de la efectividad y cumplimiento de la comunicación en cascada, que realizaban los jefes y supervisores de manera verbal a todos sus operadores, se propuso el siguiente formato mediante el cual, el área de comunicaciones de la empresa, debía levantar in situ información relevante de manera aleatoria en las diferentes áreas, es decir vencido el plazo que los líderes tenían para realizar la comunicación en cascada dentro de sus equipos de trabajo, el área de comunicación en cada una de las áreas levantaba los datos consignados en el formato de efectividad, y a su vez realizaba un levantamiento aleatorio con el público informado, con el fin de cruzar los datos e identificar oportunidades de mejora en cada líder, los resultados eran expuestos en las reuniones mensuales gerencial, y también eran fuente para los futuros entrenamientos sobre comunicación efectiva que tenían los líderes programados durante el año. 
A continuación, presentamos la implementación del formato de efectividad de comunicación:

\begin{tabular}{|l|l|l|l|}
\hline Gerencia: & & Jefatura: & \\
\hline $\begin{array}{l}\text { Nombre del líder de } \\
\text { equipo: }\end{array}$ & Puesto: & \\
\hline
\end{tabular}

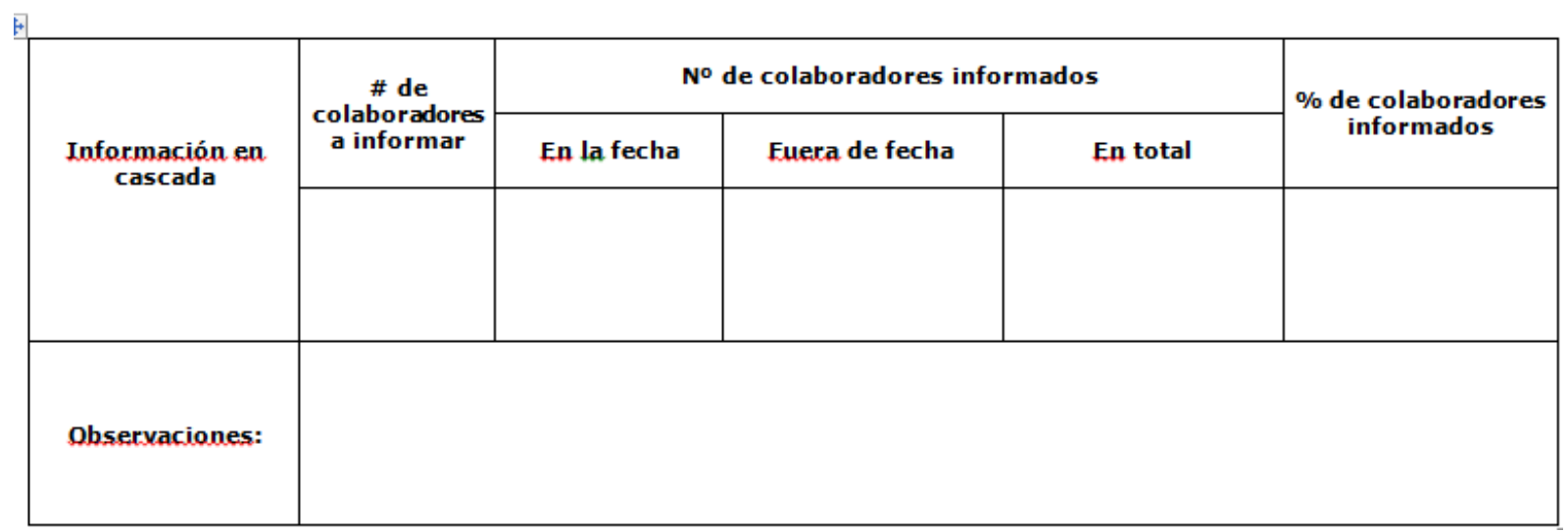

Figura 4. Formato muestra la medición de la comunicación de los líderes. Adaptado de «Cumplimiento de comunicación en cascada» por elaboración propia, 2018

\section{Ejemplos de aplicación del formato de efectividad de comunicación}

\begin{tabular}{|l|c|}
\hline Protocolo al & Inicio \\
que responde & Negociación \\
& colectiva \\
& $15 / 01 / 18$ \\
\hline
\end{tabular}

\begin{tabular}{|l|l|l|l|}
\hline Gerencia: & Operaciones I & Jefatura: & Planta de concentrado \\
\hline Nombre del líder: & Roberto Muñoz & Puesto: & Gerente \\
\hline
\end{tabular}

\begin{tabular}{|c|c|c|c|c|c|}
\hline \multirow[b]{2}{*}{ Información Cascada } & Desde & : Hasta & $\begin{array}{c}\mathrm{N}^{\circ} \text { de colaboradores a } \\
\text { informar }\end{array}$ & $\begin{array}{c}\mathrm{N}^{\circ} \text { de colaboradores } \\
\text { informados }\end{array}$ & $\begin{array}{l}\% \text { de colaboradores } \\
\text { informados }\end{array}$ \\
\hline & $15 / 01 / 18$ & $25 / 01 / 18$ & 63 & 50 & $80 \%$ \\
\hline Observaciones: & \multicolumn{5}{|c|}{$\begin{array}{l}\text { Los mensajes se difundieron a jefes de áreas y supervisores en turno } A \text { en las reuniones de coordinación de área y } \\
\text { para operadores en las reuniones de nuestro dia a dia en la guardia } A, B \text { y } C \text {. }\end{array}$} \\
\hline
\end{tabular}


Figura 5. Formato muestra la efectividad de comunicación. Adaptado de «Formato de efectividad mes de enero 2018» por elaboración propia, 2018

\begin{tabular}{|l|c|}
\hline $\begin{array}{l}\text { Inicio } \\
\text { Protocolo al } \\
\text { que responde }\end{array}$ & $\begin{array}{c}\text { Negociación } \\
\text { colectiva } \\
15 / 01 / 18\end{array}$ \\
\hline
\end{tabular}

\begin{tabular}{|l|l|l|l|}
\hline Gerencia: & Logística & Jefatura: & Logística \\
\hline Nombre del líder: & María del Pilar Cáceres & Puesto: & Gerente \\
\hline
\end{tabular}

\begin{tabular}{|c|l|l|l|l|l|}
\hline \multirow{2}{*}{ Información Cascada } & \multicolumn{1}{|c|}{ Desde } & Hasta & $\begin{array}{c}\mathbf{N}^{\circ} \text { de colaboradores a } \\
\text { informar }\end{array}$ & $\begin{array}{c}\text { No de colaboradores } \\
\text { informados }\end{array}$ & $\begin{array}{c}\text { colaboradores } \\
\text { informados }\end{array}$ \\
\cline { 2 - 6 } & $\mathbf{1 5 / 0 1 / 1 8}$ & $\mathbf{2 5 / 0 1 / 1 8}$ & 63 & $\mathbf{5 0}$ & $\mathbf{8 0 \%}$ \\
\hline Observaciones: & $\begin{array}{l}\text { Los mensajes se difundieron a jefes de áreas y supervisores en turno A en las reuniones de coordinación de área y } \\
\text { para operadores en las reuniones de nuestro dia a dia en la guardia A, B } C .\end{array}$ & \\
\hline
\end{tabular}

Figura 6. Formato muestra la efectividad de comunicación. Adaptado de «Formato de efectividad mes de febrero 2018» por elaboración propia, 2018

\begin{tabular}{|l|c|}
\hline Protocolo al & Labores \\
que responde & Indispensable \\
\hline
\end{tabular}

\begin{tabular}{|l|l|l|l|}
\hline Gerencia: & Operaciones II & Jefatura: & Procesos \\
\hline Nombre del líder: & Clara Gaitán Solar & Puesto: & Gerente \\
\hline
\end{tabular}

\begin{tabular}{|c|l|l|l|l|l|}
\hline \multirow{2}{*}{ Información Cascada } & \multicolumn{1}{|c|}{ Desde } & Hasta & $\begin{array}{c}\mathbf{N}^{\circ} \text { de colaboradores a } \\
\text { informar }\end{array}$ & $\begin{array}{c}\mathbf{N}^{\circ} \text { de colaboradores } \\
\text { informados }\end{array}$ & $\begin{array}{c}\text { \% de colaboradores } \\
\text { informados }\end{array}$ \\
\cline { 2 - 6 } & $\mathbf{0 2 / 0 3 / 1 8}$ & $\mathbf{1 0 / 0 3 / 1 8}$ & $\mathbf{5 4}$ & $\mathbf{3 5}$ & $\mathbf{6 0 \%}$ \\
\hline \multirow{2}{*}{ Observaciones: } & $\begin{array}{l}\text { El mensaje se difundió a toda la guardia del turno A y B, el mismo dia de la publicación de la lista. } \\
\text { Se complementa la cascada para el turno C con los murales informativos, flyer, } y \text { banners estratégicos. }\end{array}$ \\
\hline
\end{tabular}


Figura 7. Formato muestra la efectividad de comunicación. Adaptado de «Formato de efectividad mes de marzo 2018» por elaboración propia, 2018

Correspondía al área de comunicaciones hacer un levantamiento de cuan entendida habían sido los mensajes impartidos por los jefes, para ello realizaría entrevistas, focus group con las personas involucradas en el flujo, para así tener indicadores que nos midieran los aspectos a mejorar. Estas mediciones de efectividad se realizarían en cada área de trabajo y por líder, realizando así cortes para identificar las oportunidades de mejora de manera específica.

\section{Desarrollo de la huelga aplicando la estrategia de comunicación en cascada:}

El proceso de huelga duró cinco días, la empresa como ya avizoraba esta medida de presión, pasó a tener reuniones diarias de alineamiento con todos sus jefes y supervisores, para alinear los mensajes claves a los trabajadores que no habían acatado la huelga y difundir los impactos de una huelga improcedente y que era altamente probable sea declarada ilegal, ya que el sindicato no había cumplido los requisitos de ley para su materialización.

El objetivo de la comunicación en cascada durante los días de huelga, era en primer lugar influir en los trabajadores que aún continuaban laborando no desistan, y que a su vez sean ellos los que informen a sus compañeros huelguistas de los riesgos de mantener acatando una huelga que iba a ser declarada ilegal.

Los jefes al inicio de la jornada laboral, durante los cinco días de huelga, contabilizaban los trabajadores sindicalizados que habían decidido ir a laborar y con ellos realizaban la difusión de los mensajes claves, los mismos que diariamente eran trasladados por la gerencia de recursos humanos. Mientras tanto las mesas de diálogo avanzaban entre comisiones de negociación y no había señales de levantamiento de huelga, por ello fue vital que los jefes dentro de la empresa 
mantuvieran a sus trabajadores informados de lo que ocurría, así como trasladar la calma y respaldo de que las operaciones continuarían sin poner en riesgo su contrato de trabajo.

Dentro de los mensajes claves durante los cinco días de huelga, uno de los mensajes que se trasladaba diariamente es el mensaje en mantener la tranquilidad y concentración en las labores para que no se produzcan accidentes dentro de la jornada de trabajo, esta comunicación cara a cara con los operadores fue relevante para que no se produjeran accidentes que agravarán aún más la situación

Una vez declarada la ilegalidad de la huelga por la autoridad de trabajo competente, muchos de los trabajadores retornaron a laborar, siendo el mensaje de los líderes que se recibieran a estos trabajadores huelguistas con optimismo y dentro de un clima de calma, mensajes fuerza que fueron trasladados desde la gerencia de recursos humanos a través de los jefes. El objetivo es que se vayan reintegrando a sus labores de la manera más adecuada sin ocasionar un clima tenso.

Si bien es cierto, la ilegalidad de la huelga fue el factor preponderante para la finalización de esta medida de fuerza, la presencia de los líderes en este momento de quiebre para el sindicato, fue vital, ya que sus mensajes conciliadores y objetivos crearon la atmósfera adecuada para el clima laboral no se dañe más, ya que luego de una huelga ambas partes tanto la empresa como los trabajadores sufren un resquebrajamiento en sus relaciones, en este punto, la comunicación en cascada venía difundiendo mensajes conciliadores, y a su vez informando sobre las implicancias legales de seguir adelante con una huelga declarada oficialmente por la autoridad como ilegal.

Durante los cinco días de huelga, los jefes se tomaban mucho más tiempo en comunicarse con sus equipos, inclusive reforzó los mensajes de manera individual, tanto con los operadores que no habían acatado la huelga como con los huelguistas que retornaban a sus labores. 
Se considera que la comunicación en cascada fue una estrategia que dio un impacto colateral al proceso de negociación colectiva, ya que la empresa extendió dicho proceso a las mismas áreas operativas, posicionando poderosamente a sus jefes, que en los momento más críticos de la huelga, no solo difundían entre su personal mensajes para asegurar la producción, sino que con propiedad tenían información oficial de como se venía desencadenando la negociación, y a puertas de la declaración de la ilegalidad, estaban ya con todo el respaldo para difundir los impactos y perjuicios que podrían ocasionar a los huelguistas ilegales.

Fue la primera vez que la empresa implementaba este flujo de comunicación en cascada, más aún dentro de un proceso de negociación, con lo cual consiguió que no solo la comisión negociadora ponga fin a una huelga ilegal, sino que extendió con sus jefes la estrategia de negociación, ya que con ellos se trasladaba todos los mensajes que la empresa necesitaba difundir.

Toda la comunicación fue igual para toda la compañía, los líderes tenían una sola idea, seguían un mismo proceso. El trabajo en equipo fue muy importante y los llevó a tener un resultado muy exitoso. Posterior al resultado, no hubo ningún incidente de maltrato o queja, de parte de la gerencia general hubo el lineamiento y que fue trasladado a todos los líderes, sobre recibir a los operarios huelguista con un buen ánimo, con espíritu de equipo y positivos, sin ningún comentario negativo sobre lo sucedido, no espíritu de revanchismo.

El mensaje clave que fue hablado en toda empresa a través de los líderes fue: “¡No existen ganadores ni perdedores, somos un equipo de trabajo y continuaremos trabajando para conseguir los mismos objetivos y metas, es hora de avanzar!"

Como fin de la huelga y del proceso de negociación colectiva, esbozamos a continuación algunos de los acuerdos finales: 
- Suscripción de acuerdo entre empresa y sindicato, con el compromiso de mantener un óptimo clima laboral y privilegiar el diálogo.

- Pago de las utilidades 2017 de acuerdo a ley.

- Otorgamiento de bono económico a favor de los obreros.

- La empresa modificará las sanciones para los trabajadores que no asistieron a laborar como puestos esenciales. No aplicarían despidos.

En esta etapa final, lo líderes mantuvieron la comunicación cara a cara con sus operadores, era momento de emitir los mensajes de fin de ciclo de negociación por parte de la empresa, ya que habían conseguido poner fin a una huelga que pretendía ser indefinida, que por costumbre en Perú duran un promedio de quince días. La empresa había logrado saludables acuerdos que estaban planificados dentro de su estrategia de negociación, basada en el respeto de la ley y buena fe en los acuerdos suscritos.

Por ello, se planeó que sean los líderes quienes debían emitir los mensajes finales para cerrar el proceso de negociación de manera definitiva, a través del traslado de los siguientes mensajes claves:

- La empresa reconoce el diálogo y compromiso con la operación y con sus trabajadores.

- La Empresa mantendrá siempre disposición para el otorgamiento de mejores beneficios sin medidas de presión. El liderazgo debe extender este reconocimiento.

- Los líderes y personal de Confianza, son los representantes de la empresa, y declaran en todo momento puertas abiertas para atender toda inquietud, reclamo o duda de cualquier trabajador. 
- El bono extraordinario es la muestra de reconocimiento a la importancia de mantener la estabilidad y normalidad en la operación, saludamos el fin de la huelga ya que todos entendemos ahora que no tenía asidero legal.

- A partir de este momento reforzamos el trabajo en equipo y nuestras alianzas, reestablecemos nuestras relaciones laborales con el 100\% de los trabajadores.

- Como mensaje final se dio: ¡ Volteemos la página y construyamos juntos el futuro en la empresa!

\section{Impacto de la comunicación en cascada dentro del proceso de huelga:}

Consideramos que esta propuesta de estrategia de comunicación en cascada es un claro ejemplo, que se puede conseguir a través de la comunicación cara a cara con la gente. Se crean paradigmas que, dentro de negocios duros como el minero o industrial, las personas no muestran apertura a los mensajes directos que llaman a la reflexión o que buscan modificar actitudes, comportamientos.

Con esta estrategia de comunicación en cascada aplicada dentro de uno de los contextos más álgidos dentro de toda empresa, como lo es la materialización de una huelga, demostramos que aún en momentos de crisis es posible llegar a las personas con mensajes claros, transparentes y oportunos a través de sus jefes, con la finalidad que cada trabajador pueda tener información oficial dentro de momentos de inestabilidad.

Las reuniones de alineamiento y traslado de la información, posibilitó que las informaciones propias de la negociación no solo se quedarán dentro de la mesa de negociación, si no que sean trasladados a todos los operadores con lo cual ello facilitó que se produjeran opiniones 
y reflexiones individuales, asimismo, fortaleció en gran manera el rol y protagonismo de todos los líderes de la empresa.

Una muestra de ella son los resultados de la encuesta de clima del año 2018, en la cual los factores de: Bienestar y Respeto, Claridad y Orientación y Compromiso, subieron en dos puntos el índice de favorabilidad en comparación con la encuesta del periodo anterior. Más aún si vemos el factor de Liderazgo, el índice de favorabilidad se incrementó en 14 puntos respecto de la encuesta anterior, demostrando que los líderes eran altamente reconocidos por sus operadores.

Estos resultados fueron satisfactorios, ya que considerando que se había atravesado por una huelga, las expectativas de los resultados de la encuesta de clima realizada en junio del 2018 no debían ser provisorias, sin embargo, los resultados demostraron que los factores relacionados a liderazgo y comunicación fueron los que más se incrementaron. Como resultado general de la encuesta de clima, los resultados generales incrementaron en seis puntos el índice de favorabilidad considerando la anterior encuesta de clima laboral.

Consideramos que la estrategia de comunicación en cascada cumplió su finalidad y ayudó a cerrar una huelga indefinida en un menor tiempo considerando el promedio en el Perú, al quinto día se puso fin de esta paralización de labores manteniendo el contacto personal con cada operador que decidió no acatar la huelga, y recibiendo a los huelguistas con un espíritu integrador, todo ello dirigido por sus propios jefes a través del traslado de los mensajes de la empresa.

Consideramos que podrían extenderse esta estrategia a todos los temas que la empresa necesita trasladar a todo su personal, que no solo la comunicación en cascada sea utilizada para temas sindicales o en el caso de una huelga, sino que la empresa podría estandarizar esta manera como un protocolo de comunicación para temas de seguridad, operacionales, de relaciones comunitarias, en si para todo asunto de interés de la empresa. A la fecha la empresa viene 
trabajando en aplicar esta estrategia de comunicación de manera transversal en todas las necesidades que tenga de comunicar, asimismo, se desarrolló un plan de capacitación constante a los líderes sobre la competencia de comunicación efectiva.

Se ha demostrados que los trabajadores de un sector duro como el industrial muestran receptividad a los mensajes de la empresa incluso en medio de un momento de crisis, debido a que se cuida trasladar información objetiva, clara, oportuna y transparente.

Asimismo, los trabajadores muestran interés y se dejan influenciar, cuando perciben una auténtica preocupación de sus líderes, que retornan con respuestas a sus dudas e inquietudes, el trato cara a cara funcionó. 


\section{CONCLUSIONES}

o La presente tesis evidencia la estrategia de comunicación interna implementado fluyó de manera efectiva entre los diferentes niveles de puestos en la empresa, generando una comunicación en cascada y cara a cara durante todo el proceso de negociación colectiva; los mensajes de la empresa eran trasladados de manera oportuna, clara y transparente, influyendo de manera positiva entre los trabajadores.

o La estrategia de comunicación en cascada logró fortalecer el liderazgo de la empresa, ya que ellos fueron lo que trasladaron directamente los mensajes a sus operadores, inclusive durante los días de huelga, posicionándose como legítimos representantes de la empresa y trasladando interés genuino por sus equipos de trabajo.

o Los líderes fueron claves dentro del proceso, se les empoderó y eso logró que se sientan protagonistas del mismo, que tomen conciencia de la importancia de su rol. Esto hizo que su liderazgo sea más fuerte, logrando un mejor clima laboral y se establezcan mejor su posicionamiento antes los equipos de trabajo. Los líderes se sintieron respaldados por la empresa y satisfechos ante el logro. Con ello, se consiguió una actitud positiva y de confianza.

o A través de la comunicación en cascada realizada por los propios jefes, el nivel de confrontación, tensión e inestabilidad durante la huelga general indefinida fue manejada adecuadamente, nunca se rompió el puente de comunicación entre empresa y operadores. 
o La estrategia de comunicación interna estuvo durante todo el proceso alineada a la estrategia de negociación sindical de la empresa, se implementaron ambas estrategias las cuales estaban totalmente articuladas entre sí, logrando una percepción de estructura, organización, planificación y coherencia por parte de la empresa.

o El área de comunicaciones realizó un trabajo impecable que permitió que la estrategia se implementara tal cual fue diseñada, manteniendo la información actualizada y siendo cuidadosos con la información que brindaban hacia los líderes. Al tener un mismo estándar de seguimiento y control para la comunicación en cascada, fue más fácil realizarla y confirmarla.

o El promedio de huelgas indefinidas en el Perú, son de diez y veinte días de paralización, en el presente caso, se logró finalizar con la huelga indefinida en el quinto día de paralización de labores. Para el caso concreto, la empresa proyectó 10 días de huelga finalizando en un 50\% menor al tiempo proyectado.

o La estrategia de comunicación en cascada, logró trasladar los mensajes hacia la comisión negociadora del sindicato, dado que los mensajes de los jefes eran replicados por sus mismos operadores sindicalizados hacia los operadores huelguistas, demostrando que la comunicación fluía naturalmente. Los operadores ingresaban a un espacio de reflexión y 
fueron progresivamente retornando a sus labores. La huelga no fue acatada al $100 \%$ de los operadores.

o La empresa cuidó el clima laboral en todo momento, a pesar de que existía información tendenciosa o imprecisa que pudo afectar de manera considerable a los líderes de equipo, se manejó de manera correcta a través del seguimiento de la comunicación. Los objetivos fueron claros desde el principio y los resultados de la encuesta de clima lo respalda.

o Incremento de 06 puntos en encuesta clima laboral - HAY GROUP. Encuesta fue tomada en junio 2018 (03 meses post huelga):

- Factor de claridad y orientación: incrementó 02 puntos

- Factor de liderazgo: incrementó en 14 puntos.

o Producción estable, sin incumplimientos con clientes ni accidentes. Costos fijos durante los días de huelga, fueron compensados con el no pago de la planilla de los huelguistas. 


\section{RECOMENDACIONES}

Para prevenir estos conflictos se recomienda que la alta dirección en coordinación con el área de Recursos Humanos:

- Diseñe un plan de prevención de huelgas y solución de conflictos, que contemplen la anticipación y un enfoque estratégico de la comunicación efectiva entre los líderes y sindicalizados.

- Preparar a los líderes para estar atentos a la identificación de necesidades de los integrantes de sus equipos y satisfacción de las mismas. Cumplir su rol de líderes en asuntos de relaciones laborales y sindicales.

- Diseñar un plan de entrenamiento anual que desarrolle habilidades de liderazgo y comunicación efectiva.

- Formalizar dentro un plan de negociación de la empresa; el uso principal del estilo de comunicación “cascada" para este tipo de negociaciones, ya que permitirá que los jefes cuentan con apoyo de herramientas e información para poder trasladar los mensajes a sus colaboradores directos, de manera uniforme. Escuchando a los empleados en comités y reuniones fomentando el sentimiento de pertenencia y retroalimentación de forma permanente especialmente generando un flujo de comunicación de abajo-arriba y viceversa. 
- Implementar el flujo de comunicación en cascada para todos los temas y mensajes críticos que la empresa debe difundir a todo su personal, no solo para la negociación colectiva, institucionalizar el flujo. 


\section{REFERENCIAS BIBLIOGRÁFICAS}

Argenti, Paul A. (2014). Comunicación Estratégica y su contribución a la reputación. 1era ed. España

De Manuel Dasí, Fernando., \& Martínez-Vilanova Martínez, Rafael. (2015). Técnicas de negociación. 10ª ed. España.

Martín Artiles, Antonio, (2014) Presentación “Hacia un nuevo modelo de relaciones laborales, Anuario IET de Trabajo y Relaciones Laborales, Vol. 2, p. 1-27

Albate, J.J. (2011). Sociología del trabajo y de las relaciones laborales. Recuperado de http://www.publicacions.ub.edu/ficha.aspx?cod=07428 [Consulta: 20 de Julio de 2018]

Barrera, R. (2004). Negociación y Transformación de Conflictos: Retos entre escases y Bienestar. Guatemala: Editorial Serviprensa.

CTAIMA Outsourcing \& Consulting. (2018). El portal de la coordinación empresarial. Recuperado de http://www.coordinacionempresarial.com/quien_es_quien/ [Consulta: 05 de Agosto de 2018] 
Ministerio de Trabajo y Promoción del Empleo. (s.f.). La negociación colectiva. Recuperado de http://www.mintra.gob.pe/archivos/file/sindicatos/material_negociacion_colectiva.pdf [Consulta: 15 de Setiembre de 2018]

Niko R'L. (2014). Derechos Sindicales.

Recuperado de http://www.scribd.com/document/241357814/Derechos-Sindicales [Consulta: 07 de Julio de 2018]

Pinillo, A. A. (1996). Comunicación interna, un paseo por el tiempo. Harvard Deusto, Business Review, 48-63.

Valencia, C. (2014). Comunicación y relaciones interpersonales. Recuperado de https://prezi.com/adbdxcneshtz/comunicacion-y-relaciones-interpersonales [Consulta: 03 de Octubre de 2018]

Diario oficial El Peruano (2018). Aporte de la Minería en el PBI. Recuperado de: https://elperuano.pe/noticia-aporte-de-mineria-al-pbi-65726.aspx [Consulta: 13 de Agosto de 2018)

Ministerio de trabajo y Promoción del Empleo. (2018). Trabajo transformación Concertada. Recuperado de Utilidades:

https://www.trabajo.gob.pe/archivos/file/informacion/TRABAJADORES/INF_UTILIDA DES.pdf. [Consulta: 28 de Agosto de 2018] 
Ministerio de trabajo y Promoción del Empleo. (2018). Trabajo transformación Concertada. Recuperado de Huelga:

https://www.trabajo.gob.pe/archivos/file/informacion/TRABAJADORES/INF_HUELGA .pdf. [Consulta: 01 de Setiembre de 2018] 


\title{
ANEXOS
}

Anexo I: Nota de Prensa Sindicato

\section{SINDICATD DE TRABAJADDRES DE REFINERIA}

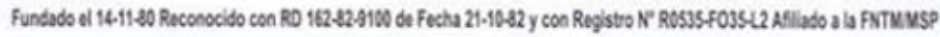

\section{NOTA DE PRENSA}

NUESTRA PATRONAL.

PRECARIZA LA RELACION LABORAL EN NUESTRO CENTRO DE TRABAJO Y NO NOS PAGA LAS UTIUDADES DESDE EL 2012!!

POR ESO ACATAREMOS UNA HUELGA GENERAL INDEFINIDA A PARTIR DEL OS DE MARZO DEL 2018, CUYOS PLAZOS LEGALES YA HAN SIDO COMUNICADOS A LA EMPRESA Y AL MINISTERIO DE

\author{
TRABAO
}

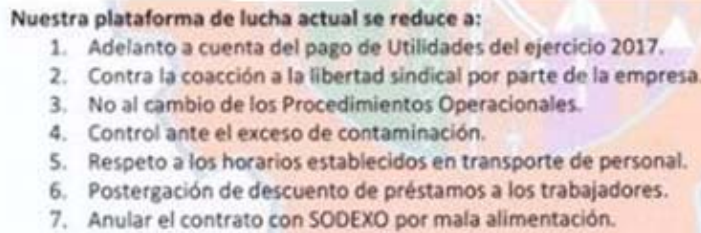

1. Adelanto a cuenta del pago de Utilidades del ejercicio 2017.

2. Contra la coacción a la libertad sindical por parte de la empresa.

3. No al cambio de los Procedimientos Operacionales.

4. Control ante el exceso de contaminación.

5. Respeto a los horarios establecidos en transporte de personal.

6. Postergación de descuento de préstamos a los trabajadores.

7. Anular el contrato con SODEXO por mala alimentación.

De no encontrar solución satisfactoria a nuestras reciamaciones en la instancia del dialogo directo, usaremos el arma de los trabajadores como es: LA HUELGA GENERAL INDEFINIDA, a partir del dia lunes 5 de marzo del aĥo en curso, responsabilizamos desde ya a la empresa de sus consecuencia como pérdidas económicas, caos social, en perjuicio de nuestras familias y la sociedad.

Para mayor información comunicarse con:

- Secretario General al celular

y/o al teléfono (01)

de nuestras oficinas administrativas.

Con el ruego de su difusión $y / 0$ propalación, auedamos de Ud.
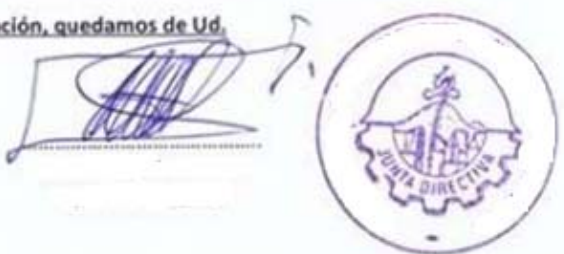
Anexo II: Estatus Sindical

De:

Gerente de Desarrollo Humano Organizacional

Enviado el:

jueves, 22 de febrero de 2018 4:24 p. m.

Para:

Gerentes

Asunto:

ESTATUS SINDICAL

Estimados, como pueden observar del mail infra nuestro asesor legal nos indica que SI es posible sancionar a toda la junta directiva por las falsas afirmaciones que vienen realizando en sus comunicados (sobre todo por la muerte de un trabajador).

Esto se activa enviando cartas a ellos para una rectificación, aguardaríamos sus respuestas formales, para analizar qué sanciones podríamos imponer. Incluso podríamos evaluar interponer una denuncia por difamación, dado que todas las afirmaciones de sus comunicados los han publicado en un medio masivo de comunicación (Facebook). Tenemos fundamentos sólidos para evidenciar que las afirmaciones son tendenciosas y falsas.

Existe base legal para sancionar e incluso denunciar, queda en nosotros tomar un posicionamiento.

Les envío el estatus. 


\section{Estatus:}

1. Asamblea General día 21 feb: aprobaron con más de 200 votos a favor: Huelga Indefinida, inicio 05 marzo.

2. Si lo acatan, deberían notificar a la empresa mañana viernes 23 feb (05 días hábiles antes).

3. Se están negando a asistir a la reunión de EEFF del día 27 feb: lo que quieren es integrar todos sus puntos en una sola reunión, lo que llaman su PLATAFORMA DE LUCHA. Enviaron hoy una carta donde se niegan a asistir día 27.

4. Estaban citados también para el día 28, para tratar en mesa redonda mensual (rutina), su supuesta plataforma de lucha. Se niegan asistir. Ejercen resistencia.

5. Empresa hoy envía respuesta formal, indicando que el tema de EEFF - Utilidades será tratado independientemente el día 27. Reitera citación.

6. Hoy conversaremos con el Jefe del Sindicato personalmente para escucharlo y trasladarle lo siguiente: a) no puede volver a utilizar instalaciones de la empresa para fines distintos a la empresa, si hay reiteración aplicaremos gestión por consecuencias. b). Empresa no se encuentra en proceso de negociación colectiva por lo tanto no atenderemos PLATAFORMA DE LUCHAS, c) la empresa está abierta al diálogo. d). el tema de EEFF y utilidades es un tema legal y lo trataremos independientemente. 
7. Se activaron planes de contingencia: operacional (asegurar producción), seguridad e infraestructura, Ministerio de Trabajo, plan de comunicación (liderazgo).

8. Si decidimos imponer sanciones por informaciones falsas sobre la muerte de trabajador: debemos redactar las cartas solicitando rectificación al Jefe del Sindicato y a toda su junta en pleno. (por alinear)

9. De realizarse la huelga será declarada ilegal, ya evaluamos con los abogados los puntos y tenemos certeza de que será ilegal, por lo que máximo podríamos ser impactados entre 12 - 15 días como máximo, lo que dura todo el proceso administrativo en el Ministerio de Trabajo. Luego de ello, analizar nuevamente imponer sanciones a huelguistas.

10. En planta ya se viene preparando el plan de contingencia para asegurar producción y seguridad para superar estos días de para si se llega a materializar la medida.

Nos mantenemos en contacto.

Un abrazo 
Anexo III: Recomendaciones Sanciones

De: Gerente de Desarrollo Humano Organizacional

Enviado el: miércoles, 21 de febrero de 2018 2:17 p. m.

Para: Gerentes

Asunto: RECOMENDACIONES SANCIONES

Adjunto en cuadro los pro y contras de imponer una sanción al Secretario General (abogado recomienda sancionar con sustento legal a nuestro favor).

Tenemos dos puntos a analizar:

Punto 1: mensaje dado en el comedor por Secretario General:

Abogado indica que tenemos sustento legal y bien podríamos bien imponer una amonestación escrita o una suspensión 1 día: sin embargo, dentro del contexto de utilidades serviría para una victimización del Secretario General. Lo que debemos hacer para no dejar la "puerta abierta", es llamarlo y sostener una conversación, donde le digamos que legalmente podríamos sancionar, sin embargo, deseamos mantener las buenas relaciones y que él NO puede tener otro comportamiento similar, porque de reincidir lamentablemente activaremos sanciones. No puede utilizar ninguna instalación de la empresa para fines distintos. 
Punto 2: mensajes falsos y tendenciosos sobre muerte del trabajador (por Secretario General y comunicado)

Impartir información falsa o tendenciosa, que involucre responsabilidad de la empresa por muerte de trabajador. Para abogado, en el propio mensaje en el comedor, Secretario General habría deslizado tendenciosamente que el trabajador salió muerto de Refinería, lo cual perjudica o involucra a la empresa de mala fe.

Sumado al contenido del último comunicado, donde se pone más directamente información falsa y se hacen aseveraciones delicadas sobre la muerte del trabajador. Este punto de acuerdo al abogado, debe ser aún más analizado, y les enviaré información detallada de cómo ocurrieron los hechos de la muerte del trabajador, para que evalúen y gradúen las posibles sanciones, incluyendo a Secretario General y naturalmente a toda la junta directiva. Luego en interno, decidiremos si es pertinente o no aplicar sanciones en medio del contexto de utilidades, respecto del punto 2.

Quedo a disposición para conversar. Saludos. 
Anexo IV: Monitoreo Redes Sociales Sindicato

De:

Comunicación Interna

Enviado el:

Lunes, 26 de febrero de 2018 3:03 p. m.

Para:

Gerentes

Asunto:

Monitoreo redes del 30 enero al 26 febrero

Datos adjuntos:

MONITOREO REDES SOCIALES SINDICATO 2018

Hola, esta nota de prensa publicada por el Secretario General este último viernes, creemos muy probable que esté ya circulando en prensa escrita y radial en medios peruanos.

Adjunto el PPT con el monitoreo de redes de la página de Sindicato y de Jefe Sindicato.

Saludos

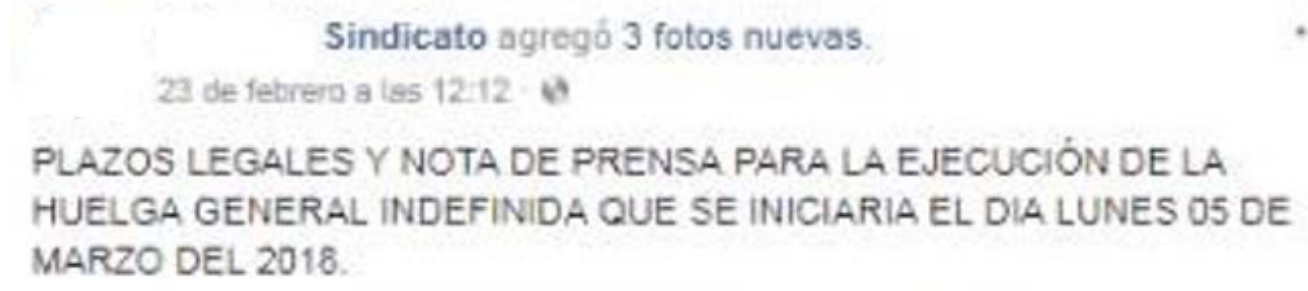




\section{Sindicato}

23 da focreco se les 10.11 st

ACUERDOS DE NUESTRA ASAMBLEA GENERAL EXTRAORDINARIA CONTINUADA DEL 21.02 .2018

agregó 4 fotos nuevas - con

$21 \mathrm{n}$.

Trabajadores

companero

haciendo Guardia ante al féretro de nuestro recordaremos

- descansa en paz compaRero, siempre te 
Anexo V: Plan comunicación interna utilidades 2017

De:

Gerente de Desarrollo Humano Organizacional

Enviado el: martes, 27 de febrero de 2018 6:40 a. m.

Para:

Equipo área de comunicación interna

Asunto:

Plan comunicación interna utilidades 2017

Estimados,

Adjunto el plan de comunicación para el tema del asunto.

Mañana a las 10:30 am se debe dar esta actualización al liderazgo en la sala (Ex comedor) Expositor: Gerente General

Por favor citar mañana a las 7:30 am al personal siguiente

- Gerentes

- Jefes de planta

- Jefes de guardia de todas las áreas incluyendo Desarrollo Humano Organizacional

- Supervisores de guardia 
De:

Gerente de Desarrollo Humano

Organizacional

Enviado el: miércoles, 7 de marzo de 2018 9:02 p.

$\mathrm{m}$.

Para:

Gerente General

Asunto:

MENSAJE A LIDERAZGO

Gerente General: sugiero que puedas dar tú este mensaje a todo el liderazgo que se pueda reunir mañana (ellos de seguro replicarán a los restantes). Creo que estamos en un momento decisivo y sería alentador recibir un mensaje tuyo, adicionalmente a los mensajes de rutina/operacionales que se dan en cada área. Creo que sería oportunidad de empezar a reestablecer confianza.

\section{MENSAJES CLAVES:}

1. El periodo 2017 ha arrojado reparto de Utilidades para todos los trabajadores. En reuniones de área podrán ser informados a detalle sobre la cantidad a repartirse por Grado Salarial. Es un concepto legal y la empresa cumplirá con el pago al $100 \%$ de su planilla, tenemos planeado pagar en marzo, la fecha legal límite es 2 de mayo.

2. Si bien es cierto, la empresa indicó en los años pasados, que cuando se arrojen utilidades ya no se entregará bono; este año la empresa entiende las expectativas de sus trabajadores 
y tiene la disposición de otorgar un bono como liberalidad aparte de las utilidades. Este es el contexto de este año, analizaremos en su momento los años por venir.

3. Para el otorgamiento de esta liberalidad, la condición es dialogar responsablemente, pero NO en huelga, no conversamos con medidas de presión. Consideramos en este bono prioritariamente a todo nuestro liderazgo y personal de confianza. Aún no tenemos las cifras finales, pero puedo adelantar que se otorgará lo que responsablemente esté en la posibilidad de la empresa, estamos analizando.

4. La empresa continúa el diálogo con el Sindicato escuchando y analizando su solicitud de bono y aplazamiento de adelanto de utilidades 2017. Agradecemos la buena disposición de Sindicato y el compromiso que vienen demostrando. Es importante valorar y agradecer a cada uno de ellos (el uno a uno), así como a nuestros NO sindicalizados, por ellos seguimos operando.

5. Estamos entrando en la etapa final de este proceso de huelga, ya fue declarada ilegal este pasado 06 de marzo, y estamos a la espera del último pronunciamiento y confirmación de la ilegalidad por parte del ministerio, entendemos que ocurrirá por inicio de la siguiente semana.

6. Nuestra estrategia está basada en nuestro ser y normalidad operacional, debemos resguardar primero a las personas (prioritariamente a ustedes nuestro personal de 
confianza, y a todos nuestros trabajadores) y asegurar nuestra operación. Valoramos el trabajo desplegado por ustedes en estos momentos de crisis, ustedes son la cabeza de la planta, son el personal en quienes confiamos.

7. El proceso anterior de huelga no fue bueno para ninguno de nosotros. Por ello estamos avanzando ahora a paso seguro, con alineamiento de nuestras directorias y analizando la toma de decisiones objetivas, responsables y constructivas. Aún faltan días, sigamos adelante dando lo mejor de nosotros. ¡iEstamos juntos!!

Atentamente,

Gerente Desarrollo Humano Organizacional 
Anexo VII: Formato de comunicación en cascada

\section{Comunicación Cara a Cara}

Protocolo de Comunicación

Tema: Inicio Negociación Colectiva

Fecha: 15/01/2018

$\ddagger$

Ảrea que comunica: Desarrollo Humano Organizacional

Este mensaje debe ser difundido a los siguientes niveles:

\begin{tabular}{|l|l|}
\hline & Gerentes \\
\hline $\mathrm{X}$ & Jefes \\
\hline $\mathrm{X}$ & Supervisores \\
\hline
\end{tabular}

\begin{tabular}{|l|l|}
\hline $\mathrm{X}$ & Analistas \\
\hline $\mathrm{X}$ & Operadores y Técnicos \\
\hline & Practicantes \\
\hline
\end{tabular}

\section{MENSAJE A DIFUNDIR:}

- Puentes de diálogo: la empresa dio inició a la negociación colectiva priorizando la comunicación clara y transparente con todos sus trabajadores, siendo objetivo que dicho proceso se desarrolle dentro de un ambiente de buena fe, respeto por los acuerdos tomados dentro del cumplimiento de la ley".

- Confianza en sus trabajadores: "Estando en el inicio de la negociación con el sindicato, la empresa confia en que la actitud de sus trabajadores será de responsabilidad y buena fe, en el cumplimiento de sus labores y concentración de sus tareas, identificando riesgo en el trabajo a fin de prevenir accidentes; la negociación sindical no debe ser motivo de distracción, más bien, aguardar con expectativa los resultados a los que llegarán ambas comisiones negociadoras".

- Posición de la empresa: "Desde el inicio de la negociación, la empresa manifiesta a todos sus trabajadores, que será firme en requerir al sindicato que se cumplan los acuerdos previos respecto al tema de pago de utilidades, como todos sabemos, para el año 2018 no se pagarán los bonos extraordinarios, ya que los trabajadores recibirán el reparto de utilidades, de acuerdo a nuestros valores, debemos respetar los acuerdos suscritos." 


\section{PUNTOS FOCALES:}

- Se dio inició a la negociación colectiva priorizando la comunicación clara y transparente con todos sus trabajadores.

- Confiamos en que la actitud de sus trabajadores será de responsabilidad y buena fe, en el cumplimiento de sus labores y concentración de sus tareas.

- La empresa será firme en requerir al sindicato que se cumplan los acuerdos previos respecto al tema de pago de utilidades.

DUDAS:

Cada gestor deberá absolver las dudas

PLAZO PARA QUE SE COMUNICADO:

Hasta el 25 de enero 2018 
Anexo VIII: Formato de comunicación en cascada

\section{Comunicación Cara a Cara}

Protocolo de Comunicación

Tema: Declaración de Improcedencia de la Huelga

Fecha: 28/02/2018

†

Área que comunica: Desarrollo Humano Organizacional

Este mensaje debe ser difundido a los siguientes niveles:

\begin{tabular}{|l|l|}
\hline & Gerentes \\
\hline$X$ & Jefes \\
\hline$X$ & Supervisores \\
\hline
\end{tabular}

\begin{tabular}{|l|l|}
\hline$X$ & Analistas \\
\hline$X$ & Operadores y Técnicos \\
\hline & Practicantes \\
\hline
\end{tabular}

MENSAJE A DIFUNDIR:

- Declaración de Improcedencia de la Huelga: "Todos los trabajadores deben conocer que el Ministerio de Trabajo acaba de declarar improcedente la huelga, lo cual tendrá repercusiones legales si se continúa con la paralización, la empresa exhorta a todos sus trabajadores a reanudad sus labores y no generar un clima de inestabilidad."

।

DUDAS:

Cada gestor deberá absolver las dudas

PLAZO PARA QUE SE COMUNICADO:

Hasta el 01 marzo 2018 
Anexo IX: Formato de comunicación en cascada

\section{Comunicación Cara a Cara}

Protocolo de Comunicación

Tema: Labores Indispensables

Fecha: 02/03/2018

A Ȧrea que comunica: Desarrollo Humano Organizacional

Este mensaje debe ser difundido a los siguientes niveles:

\begin{tabular}{|l|l|}
\hline & Gerentes \\
\hline $\mathrm{X}$ & Jefes \\
\hline $\mathrm{X}$ & Supervisores \\
\hline
\end{tabular}

\begin{tabular}{|l|l|}
\hline$X$ & Analistas \\
\hline$X$ & Operadores y Técnicos \\
\hline & Practicantes \\
\hline
\end{tabular}

\section{MENSAJE A DIFUNDIR:}

- Labores indispensables: "Se anima a todos los trabajadores a ser respetuosos de sus turnos de trabajo, ya que si bien la empresa respeta la huelga de sus trabajadores, existe un grupo de trabajadores que si deben asistir a laborar por encontrarse dentro de la relación de labores indispensables, ya que la ley nos faculta a preservar aquellos puestos de trabajo que son indispensables para no paralizar totalmente la producción, revisar los paneles colocados en la puerta de ingreso a la empresa".

\section{PUNTOS FOCALES:}

Se les pide a todos los trabajadores revisar los paneles y banner colocados en la puerta de ingreso a la empresa, así como en los murales para conocer la lista de las personas que deben asistir a laborar por encontrarse dentro de la relación de labores indispensables.

\section{DUDAS:}

Cada gestor deberá absolver las dudas

\section{PLAZO PARA QUE SE COMUNICADO:}

Hasta el 03 marzo 2018 